\title{
Attenuation of nociceptive and paclitaxel-induced neuropathic pain by targeting inflammatory, CGRP and substance P signaling using 3-Hydroxyflavone
}

\author{
Rahim Ullah $^{\text {a, }}$, Gowhar Ali ${ }^{\mathrm{a}}$, Fazal Subhan ${ }^{\mathrm{b}}$, Muhammad Naveed ${ }^{\mathrm{c}}$, Ajmal Khan ${ }^{\mathrm{d}, * *}$, \\ Jawad Khan $^{\text {a }}$, Sobia Ahsan Halim ${ }^{\mathrm{d}}$, Nisar Ahmad ${ }^{\mathrm{e}}$, Zakiullah ${ }^{\mathrm{a}}$, Ahmed Al-Harrasi ${ }^{\mathrm{d}}$, \\ ${ }^{a}$ Department of Pharmacy, University of Peshawar, Peshawar, 25120, Pakistan \\ ${ }^{\mathrm{b}}$ Department of Pharmacy, Cecos University of Science and Technology, Peshawar, Pakistan \\ ${ }^{\mathrm{c}}$ Department of Pharmacology and Pharmacotherapy, Faculty of Medicine, University of Szeged, Szeged, Hungary \\ d Natural and Medical Sciences Research Center, University of Nizwa, Birkat-ul-Mouz 616, Nizwa, Oman \\ e Department of Pharmacy, National University of Pakistan, Pasrur Road, Sialkot, Punjab, Pakistan
}

\section{A R T I C L E I N F O}

\section{Keywords:}

Paclitaxel

Cytokines

Neuropathic pain

3-Hydroxyflavone

Substance P

CGRP

NF- $\mathrm{B}$

\begin{abstract}
A B S T R A C T
Paclitaxel is an anti-microtubule agent, most widely used chemotherapeutic agent for the treatment of malignant solid tumors. However, it is associated with some severe side effects including painful neurotoxicity with reporting of neuropathic pain and sensory abnormalities by patients during and after paclitaxel therapy. Peripheral neuropathy was induced by the administration of paclitaxel ( $4 \mathrm{mg} / \mathrm{kg}$ on days $1,3,5$, and 7). In this study, the anti-nociceptive and anti-inflammatory propensity of 3-Hydroxyflavone (3HF) in mice and the preventive effect of $\mathbf{3 H F}$ against paclitaxel-induced peripheral neuropathy in Sprague Dawley (SD) rats were investigated. Moreover, tactile and cold allodynia, thermal and tail immersion hyperalgesia, and effects on motor-coordination were also evaluated. Furthermore, the expression of proinflammatory cytokines i.e. Calcitonin gene-related peptide (CGRP), and Substance P from the spinal cord was examined through RT-PCR. Additionally, a computational structural biology approach was applied to search the potential therapeutic targets and to predict the binding mechanism of $3 \mathbf{H F}$.

Treatment of 3HF alleviated the nociceptive pain, paw edema, development of tactile and cold allodynia, and hyperalgesia. Similarly, treatment with 3HF suppressed the paclitaxel-induced increase in mRNA expression of several inflammatory cytokines including tumor necrosis factor $-\alpha$ (TNF- $\alpha$ ), interleukin-1 $\beta$ (IL-1 $\beta$ ), and interleukin-6 (IL-6), CGRP, and Substance P. However, the daily treatment of 3HF did not affect the motor behaviors of rats. The inhibitory mechanism of $3 \mathbf{H F}$ in neuropathic pain is predicted with extensive computational bioinformatics approach which indicates that the 3HF effectively interacts with the binding domains of Nuclear factor-kappa B (NF-кB), CGRP receptor and the receptor of Substance P to exert its inhibitory activities. However, the computationally predicted binding affinities revealed that the potential of binding of the compound with Substance P receptor (Neurokinin 1 receptor) is higher than the other receptors; there NK1R could be the most possible binding target of 3HF. These findings indicate that 3HF has anti-nociceptive, anti-inflammatory, and anti-neuropathic pain effects against paclitaxel-induced neuropathic pain.
\end{abstract}

\section{Introduction}

Neuropathic pain is a chronic pathological pain, caused by functional and structural damage of the sensory nervous system (Akbar et al., 2016). It is characterized by hypersensitivity to noxious (hyperalgesia) and non-noxious (allodynia) stimulation (Sałat, 2020). Numerous

\footnotetext{
* Corresponding author. Department of Pharmacy, University of Peshawar, Peshawar, Pakistan..

** Corresponding author. University of Nizwa, Oman.

E-mail addresses: Rphrahimullahstd@uop.edu.pk, rphrahimullah@gmail.com (R. Ullah), gowhar_ali@uop.edu.pk (G. Ali), subhan@cecos.edu.pk (F. Subhan),

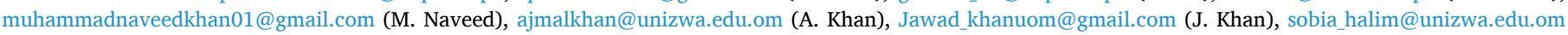
(S.A. Halim), nisarahmadsatal@yahoo.com (N. Ahmad), Zakiullah@uop.edu.pk (Zakiullah), aharrasi@unizwa.edu.om (A. Al-Harrasi).
} 
studies have revealed that peripheral nerve injury produces heterogeneous, prolongs pain conditions called neuropathic pain (Khan et al., 2016). Chronic neuroinflammation in peripheral and central nervous systems plays a vital role in the cause and maintenance of neuropathic pain (Hughes et al., 2012). However, in several animal models of neuropathic pain, the elevated level of inflammatory cytokines have been observed in injured tissues like dorsal root ganglion (DRG), spinal cord, and brain regions responsible for the propagation of pain (Lees et al., 2013; Vickers, 2017). Inflammatory mediators such as IL-1 $\beta$, IL-6, and TNF- $\alpha$ are stimulated through the activation of a transcription factor called nuclear factor kappa-light-chain-enhancer of activated B cells (NF-kB) (Naveed et al., 2019), which decreases the threshold of pain by sensitizing nociceptors directly (Sandkuhler, 2009). Moreover, several neuropeptides (Substance $\mathrm{P}$, calcitonin gene-related peptide) are released within the dorsal horn and play a pivotal role in pain regulating responses (Chen et al., 2015).

Neuropathy is initiated from nerve damage including HIV neuropathy, diabetic-induced neuropathy, drug-induced neuropathy, postherpetic neuralgia, and traumatic nerve injury (Khan et al., 2016). Neuropathic pain syndrome is associated with many first-line chemotherapeutic agents (Onodera et al., 2013). Paclitaxel is the preferred chemotherapy agent for solid tumor treatment in clinical practices (Gordon et al., 2011). However, it is associated with long lasting and dose-limiting side effect like peripheral neuropathy (Manjavachi et al., 2019). Paclitaxel-induced neuropathy is characterized by hypersensitivity to cold and mechanical stimuli that occur early at the treatment initiation ( $\mathrm{Fu}$ and Gordon, 1997). Spinal cord inflammation plays important role in chemotherapy-induced peripheral neuropathy, with released of pro-inflammatory chemokines contributing to central sensitization (Manjavachi et al., 2019). Likewise, such inflammatory mediators releases in the peripheral nervous system following chemotherapy, due to activation of glial cell and the mononuclear leukocytes infiltration into the dorsal root ganglions (DRG), contributes to the enhancement of neuronal excitability (Liu et al., 2014; Warwick and Hanani, 2013).

Paclitaxel-induced peripheral neuropathy is one of the chemotherapeutic agent-induced peripheral neuropathy (CIPN), used to develop animal models to understand the mechanism of neuropathic behaviors and for the design and discovery of new anti-neuropathic agents (Khan et al., 2016; Zhang et al., 2019). Neuropathy is a dose-limiting adverse effect of chemotherapy. Paclitaxel-induced neuropathic pain is one of the most frequently seen neuropathic pain in the clinic and is observed in up to $80 \%$ of patients treated with paclitaxel (Sisignano et al., 2014). There is no safe and effective therapy available for the treatment of this painful condition (Zhang et al., 2019).

The available therapy for chronic neuropathic pain management includes anti-depressants, opioids, and anti-epileptics, however due to their severe adverse effects, their use in attenuation of peripheral neuropathy is limited (Sisignano et al., 2014). Therefore, effective alternative therapy with the promising effect is instantly required for the treatment of neuropathic pain.

Flavonoids are beneficial for human health and present in a variety of plants, dietary substances, and in the synthetically produced form (Tapas et al., 2008). Flavonoids have shown potent anti-oxidant, anti-inflammatory, anxiolytic, anti-nociceptive, neuroprotective, and anti-neuropathic properties. Moreover, flavonoids interact with various neurotransmitter systems (GABA, serotonin, dopamine, glycine) involved in neuroprotection and neuronal activity modulation (Shahid et al., 2017b). In this regard, the neuroprotective effect of $\mathbf{3 H F}$ in paclitaxel-induced neuropathic pain animal model was evaluated along with tactile and cold allodynia, thermal and tail immersion hyperalgesia, and effects on motor-coordination. Additionally, attempts were made to investigate the potential mechanisms of neuroprotective effect and anti-neuropathic properties of 3-Hydroxyflavone, for this purpose, the expression of proinflammatory cytokines, CGRP, and Substance P were examined in the spinal cord through RT-PCR. Furthermore, computational structural biology was employed to predict the binding mechanism of 3HF.

\section{Materials and methods}

\subsection{Chemicals and reagents}

3HF and Naloxone (Sigma, USA), Paclitaxel (Alfa Aesar, Thermo Fisher Scientific, Germany), dimethyl sulfoxide (DMSO, Unichem, USA), Tween-80 (80\%, Scharlau, Spain), TRI-reagent (Bioshop, Canad), cDNA synthesis kit (abm, Canada), PCR master mix (Thermo Fisher Scientific, Germany), PCR primers (Macrogen Korea), DNA ladder (Invitrogen US) agarose, Boric acid and ethidium bromide (Sigma-Aldrich USA) were used. 3HF was dissolved in a vehicle containing normal saline, DMSO, and Tween-80 in a ratio of 95:04:01.

\subsection{Animals}

Sprague-Dawley male rats (SD, 200-250 g) and Albino mice (18-30 g) were bred and maintained at $22.0 \pm 2.0^{\circ} \mathrm{C}$ with $12 / 12 \mathrm{~h} \mathrm{light/dark}$ cycle in the animal house of the Department of Pharmacy, University of Peshawar, Pakistan. The experimental procedures were approved by the departmental ethical committee of the University of Peshawar (Approval no. 12/EC-17/Pharm) and were performed under the rules of the UK Animals (Scientific Procedures) Act 1986. All experiments were carried out during day time (8:0 a.m. to 4:0 p.m.). The schedule for experiments using mice and rats are shown in Fig. 1.

\subsection{Anti-nociceptive activities}

To evaluate the peripheral and central anti-nociceptive activities of 3HF in mice (18-22 g); Acetic-acid induced writhing and hotplate test were used (Rukh et al., 2020; Subhan et al., 2010). The antagonistic effect of Naloxone on the anti-nociceptive activity of 3HF using a hot plate model was also investigated in mice.

\subsubsection{Acetic acid-induced writhes}

Writhing test is a chemical method of pain induction of peripheral origin by injection of irritant like acetic acid in mice. The decrease in the writhing frequency indicted analgesic activity of the test compound (Gawade, 2012). Mice were deprived of food for $2 \mathrm{~h}$ before the start of any experiment. The animals were divided into five groups including; vehicle $10 \mathrm{ml} / \mathrm{kg}$ (Group I), a standard analgesic Diclofenac $50 \mathrm{mg} / \mathrm{kg}$ (Group II), and test drug 3HF of three different doses (25, 50, and 75 $\mathrm{mg} / \mathrm{kg}$ ) (Group III, IV, V). All mice were administered intraperitoneally $30 \mathrm{~min}$ before the injection of $10 \mathrm{ml} / \mathrm{kg}$ acetic acid (1\%). The number of writhes (abdominal contraction) induced by acetic acid was measured for $20 \mathrm{~min}$ (Subhan et al., 2010). The percent-antinociceptive effect was calculated from the number of writhes as; [\%-Inhibition $=1$ - test/vehicle) $\times 100]$.

\subsubsection{Hot plate activity}

It is used for the evaluation of the central anti-nociceptive potential of drug (Brochet et al., 1986). The anti-nociceptive effect of the test drug was tested in mice using a hot plate analgesiometer maintained at 54.0 $\pm 0.10^{\circ}$. The animals were divided into 5 groups including; vehicle 10 $\mathrm{ml} / \mathrm{kg}$ (Group I), a standard analgesic Tramadol $30 \mathrm{mg} / \mathrm{kg}$ (Group II), and test drug $3 \mathrm{HF}$ of three different doses $(25,50$, and $75 \mathrm{mg} / \mathrm{kg}$ ) (Group III, IV, V). The vehicle, tramadol, and $3 \mathbf{H F}$ were injected intraperitoneally, the latency time in seconds of animal's withdrawal responses on the hot plate was noted at intervals of 30,60 , and $90 \mathrm{~min}$. The \%-antinociceptive activity was calculated from the latencies as; [\%-Protection $=($ test - baseline $) /($ cut-off - baseline $) \times 100$ ] (Rukh et al., 2020). 
Exp 1-3 Anti-nociceptive studies (Mice)

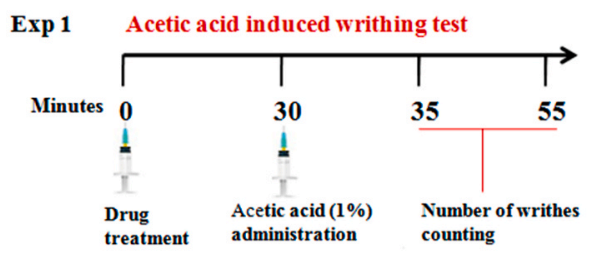

Exp 2 Hotplate test

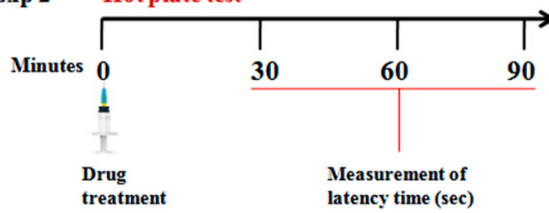

Exp 3 Antagonistic study

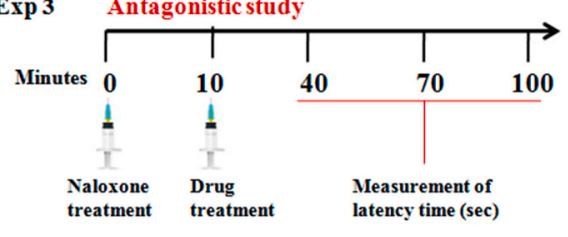

Exp 4-6 Anti-inflammatory studies (Mice)

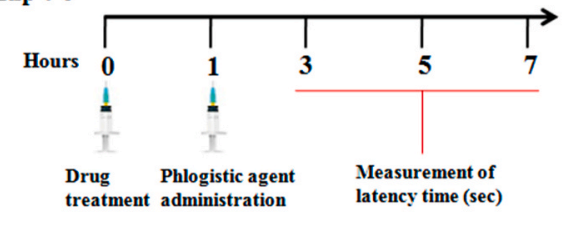

Phlogistic agents: Carrageenan, Histamine, and Serotonin Exp: Experiment

\section{Exp 7 Anti-neuropathic study (Rats)}

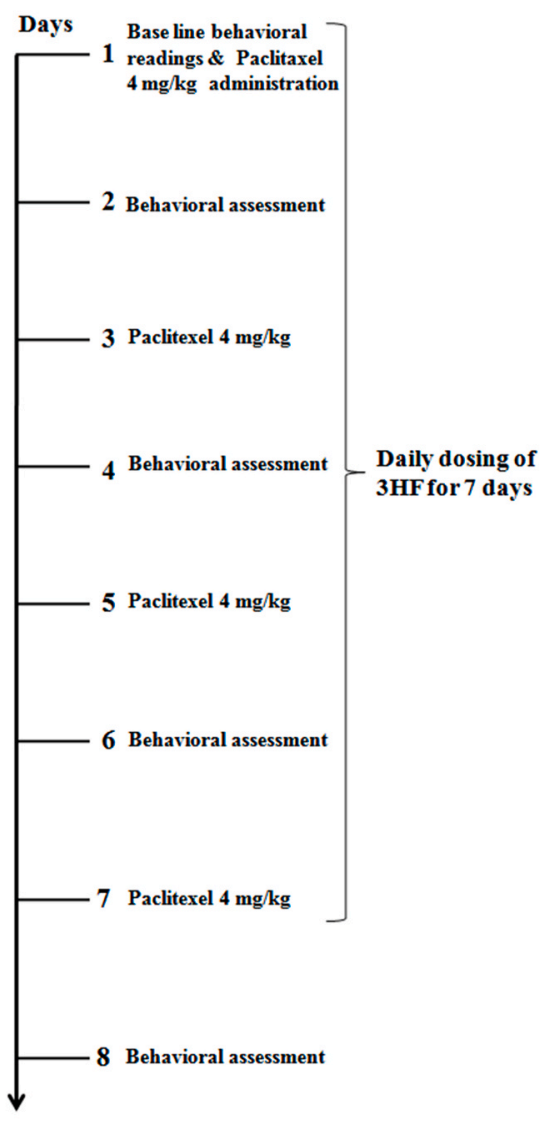

Fig. 1. Schedule for experiments.

2.3.3. Effect of naloxone on anti-noceciptive activity of $3 \mathrm{HF}$ on hot plate model

To evaluate the antagonistic effect of Naloxone against 3HF, the animals were divided into ten groups ( $n=6 /$ group). All the animals were kept fasting for $2 \mathrm{~h}$ before the start of the experiment (Subhan et al., 2010). Drugs were administered intraperitoneally to all animals (Table 1), and the latency times were recorded at 30,60, and $90 \mathrm{~min}$ intervals after drug administration. The Naloxone was administered subcutaneously $10 \mathrm{~min}$ prior to the vehicle, tramadol, and $\mathbf{3 H F}$ administration (Ahmad et al., 2017a).

\subsection{Anti-inflammatory activities}

Carrageenan, histamine, and serotonin-induced paw edema tests are used for the evaluation of anti-inflammatory drugs. Paw edema developed by carrageenan is a biphasic event. The release of cytokines,

Table 1

Grouping of animals.

\begin{tabular}{ll}
\hline Groups & Drugs administered intraperitoneally \\
\hline Group 1 & Vehicle $(10 \mathrm{ml} / \mathrm{kg})$ \\
Group 2 & Vehicle $(10 \mathrm{ml} / \mathrm{kg})+$ naloxone $(1 \mathrm{mg} / \mathrm{kg})$ \\
Group 3 & Tramadol $(30 \mathrm{mg} / \mathrm{kg})$ \\
Group 4 & Tramadol $(30 \mathrm{mg} / \mathrm{kg})+$ naloxone $(1 \mathrm{mg} / \mathrm{kg})$ \\
Group 5 & 3HF $(25 \mathrm{mg} / \mathrm{kg})$ \\
Group 6 & 3HF $(25 \mathrm{mg} / \mathrm{kg})+$ naloxone $(1 \mathrm{mg} / \mathrm{kg})$ \\
Group 7 & 3HF $(50 \mathrm{mg} / \mathrm{kg})$ \\
Group 8 & 3HF $(50 \mathrm{mg} / \mathrm{kg})+$ naloxone $(1 \mathrm{mg} / \mathrm{kg})$ \\
Group 9 & 3HF $(75 \mathrm{mg} / \mathrm{kg})$ \\
Group 10 & 3HF $(75 \mathrm{mg} / \mathrm{kg})+$ naloxone $(1 \mathrm{mg} / \mathrm{kg})$ \\
\hline
\end{tabular}

bradykinin, histamine, and serotonin occurs in the initial phase of edema. While the release of prostaglandins take place in the second phase of edema (Rodrigues et al., 2016; Vasudevan et al., 2007). Histamine and serotonin are important inflammatory mediators, they cause vasodilation and enhanced vascular permeability (Cuman et al., 2001; Linardi et al., 2000).

The anti-inflammatory efficacy of $\mathbf{3 H F}$ was studied using the mouse models of carrageenan (Munir et al., 2020; Winter et al., 1962), histamine (Naveed et al., 2019; Singh et al., 1996), and serotonin (Cole et al., 1995; Rukh et al., 2020) induced paw edema tests. The animals were administered with vehicle, diclofenac $(50 \mathrm{mg} / \mathrm{kg}$, i. p.), chlorpheniramine $(10 \mathrm{mg} / \mathrm{kg}$, i. p.), mianserin ( $1 \mathrm{mg} / \mathrm{kg}$, s. c.), and $3 \mathrm{HF}$ at doses of 25,50 , and $75 \mathrm{mg} / \mathrm{kg}$ (i.p.). The phlogistic agents were injected into the subplantar region and the edema was measured at $1,3,5 \mathrm{~h}$ after administration of phlogestic agents using a digital plethysmometer. In each inflammation paradigm, the change in edema was determined $(\Delta$ $=$ post-dose paw volume - baseline paw volume) and the anti-inflammatory response in percent was calculated as [\%-inhibition $=$ $(1-\Delta$ test $/ \Delta$ vehicle $) \times 100]$.

\subsection{Induction of neuropathic pain and drug administration}

Paclitaxel is natural anti-cancer drug; causes chemotherapy-induced peripheral neuropathy, which adversely affects the treatment course and quality of the patients (YAŞAR et al., 2020). Male SD rats were injected intraperitoneally (i.p.) Paclitaxel ( $4 \mathrm{mg} / \mathrm{kg}$ ) or vehicle four times a week (on days 1, 3, 5, and 7). 3HF was injected (i.p.) once a day for seven days. Behavioral experiments were performed before drug administration and on days $2,4,6$, and 8 . Animals were sacrificed on day 8 for 
sample collection (Tsutsumi et al., 2016). The animals were distributed randomly in the following groups $(\mathrm{n}=8)$.

Group I: Vehicle.

Group II: Paclitaxel (4 mg/kg, 4 times/week, i. p) + Vehicle.

Group III: Paclitaxel (4 mg/kg, 4 times/week, i. p) + Gabapentin 75 $\mathrm{mg} / \mathrm{kg}$ (once daily for 7 days i. p).

Group IV: Paclitaxel (4 mg/kg, 4 times/week, i. p) + 3HF 25 mg/kg (once daily for 7 days i. p).

Group V: Paclitaxel (4 mg/kg, 4 times/week, i. p) + 3HF $50 \mathrm{mg} / \mathrm{kg}$ (once daily for 7 days i. p).

Group VI: Paclitaxel (4 mg/kg, 4 times/week, i. p) + 3HF 75 mg $/ \mathrm{kg}$ (once daily for 7 days i. p).

\subsubsection{Behavioral experiments}

\subsubsection{Evaluation of tactile allodynia in paclitaxel-induced rats.} Tactile allodynia was assessed before first drug administration and on days 2, 4, 6, and 8, using a series of von Frey filaments (15, 8, 6, 4, 2, 1.4, $1,0.6$, and $0.4 \mathrm{~g}$ ) (Touch Test ${ }^{\circledR}$ Sensory Evaluators, North Coast, USA), were applied to the mid plantar area of the hind paw of rats perpendicularly, to an extent that caused the filament to bend. Each filament was applied for $6 \mathrm{~s}$ (cut off time) or until withdrawal response (lifting of paw, licking, or flinching) displayed by the animal. The force $15 \mathrm{~g}$ was considered as a cutoff force. To evade any influence of former stimuli on rat behavior, the filaments were applied at intervals of several seconds. The stimulus was repeated in case of an indefinite response. The paw withdrawal threshold (PWT) in both hind-paws was measured with a 5 min interval and the mean value of three readings was calculated (Ali et al., 2015).

2.5.1.2. Evaluation of cold allodynia (acetone test). Animals were habituated for $30 \mathrm{~min}$ by placing underneath the inverted transparent box on the shelf with a meshed wire floor. After habituation, $0.05 \mathrm{~mL}$ acetone was applied 3 times alternatively to the mid-plantar surface of each hind paw at $30 \mathrm{~s}$ of the interval using one C.C syringe, and the duration of paw withdrawal of response (PWD) (liking, biting or flinching) was recorded.

This test was performed by gently touching the mid-plantar skin of the hind paws with $50 \mu \mathrm{L}$ acetone. Prior to this test, animals were habituated for $30 \mathrm{~min}$ in a transparent box on a shelf with a meshed wire floor. After habituation, $0.05 \mathrm{~mL}$ acetone was applied 3 times alternatively to the mid-plantar surface of each hind paw at $30 \mathrm{~s}$ of the interval using one C.C syringe, and the duration of paw withdrawal response (PWD) (liking, biting, or flinching) was recorded (Shahid et al., 2017a).

2.5.1.3. Evaluation of thermal hyperalgesia. Thermal hyperalgesia test was performed using hot-plate (Harvard apparatus, USA), maintained at $52.0 \pm 0.20^{\circ} \mathrm{C}$. The animals were kept on the hot plate and response latency time (sec) was recorded either by jumping or lifting/licking of hind-paws. To avoid tissue damage, 1 min was adopted as a cut-off time. The response latency time was assessed before the first drug administration and on days $2,4,6$, and 8 . The response latency of each rat was measured in triplicate and the average value from 3 readings was taken as nociceptive response latency (Ahmad et al., 2017b).

2.5.1.4. Hot water tail immersion test. To assess the central antinociceptive activity of $\mathbf{3 H F}$, tail immersion test in hot water was carried out. Briefly, the tip of the rat tail was immersed in hot water $\left(46^{\circ} \mathrm{C}\right)$, until withdrawal of tail occurred. The tail immersion duration was recorded with $15 \mathrm{~s}$ cutoff time. Each rat was subjected to three trials with 5 min interval and average value was calculated. Test was performed before any drug treatment and post drug treatment on days $2,4,6$, and 8 (Authier et al., 2003).

2.5.1.5. Cold water tail immersion test. Tail cold-allodynia was assessed by dipping the tail tip in ice-cold water $\left(4^{\circ} \mathrm{C}\right)$ and tail withdrawal latency (TWL) in seconds to withdrawal reflexes was recorded. To prevent tissue damage, a cut-off time of $15 \mathrm{~s}$ was imposed. The test was performed three times for each rat and average of three measurements was calculated. Furthermore, test was carried out prior to first drug administration and on days 2, 4, 6, and 8. Normal animals respond rarely within $15 \mathrm{~s}$, while neuropathic animals respond frequently (Polomano et al., 2001).

2.5.1.6. Effects of 3HF on muscle strength and motor activity. Rotarod test was carried out to assess the effect of $3 \mathbf{H F}$ on motor coordination. Rats were placed on the rotarod, rotating with the increasing speed (4-40 rotations per minute) over $5 \mathrm{~min}$; animals were forced to move forward to prevent falling off. The falling off time of animals fell from rotatingdevice was noted. The effect on motor-performance was assessed prior to first drug administration and on days 2, 4, 6, and 8 (Shahid et al., 2017a).

\subsubsection{Reverse transcriptase polymerase chain reaction}

Total RNA was extracted from the spinal cord (L4-L6) segments using TRI-reagent according to the manufacturer's instructions. The purity of RNA was confirmed using UV-spectrophotometer. RNA was converted to cDNA through a cDNA synthesis kit. The PCR primers (TNF- $\alpha$, IL-1 $\beta$, IL6 , CGRP, and Substance P) are listed in Table $2 \beta$-actin was used as an internal control. Agarose gel (1.5\%) was used for amplified product separation. The mRNA expression was calculated in the arbitrary unit using ImageJ software (Ullah et al., 2020).

\subsubsection{Molecular modeling}

The molecular targets of $\mathbf{3 H F}$ were searched through a literature survey (Ahmed et al., 2019). The binding affinity of 3-hydroxy flavone with the selected targets was predicted by the molecular docking approach. Docking was carried out on Molecular Operating Environment (MOE v 2009.14). The three-dimensional structures of selected targets (Nuclear factor $\mathrm{\kappa B}$ (PDB code: $1 \mathrm{NFK}$ ), Substance P Receptor (Neurokinin 1 receptor, PDB code: 6HLP) and Calcitonin Gene-Related Peptide Receptor, PDB code: 6E3Y) were downloaded from RCSB Protein Databank (RCSB-PDB, https://www.rcsb.org/). Hydrogen was added and partial charges were applied on proteins based on Amber 12: EHT force field of MOE. The heteroatoms other than ligands were removed. Similarly, water molecules within the vicinity of $3 \AA$ of the binding site were retained, while the rest of the water molecules were removed from protein structures. The PDB structures were then used in the molecular docking using the Triangle Matcher docking method and London dG scoring function of MOE. For docking, induce fit docking protocol was applied in order to assess the receptor conformational flexibility during docking. The 3D-structure of 3HF was built and minimized on MOE with MMFF94 $\times$ force field with gradient $=0.1$ RMS $\mathrm{kcal} / \mathrm{mol} / \AA$ A with default parameters (eps = r, cutoff).

Table 2

Primers sequences for PCR reaction are shown in table.

\begin{tabular}{|c|c|}
\hline Primer & Sequence \\
\hline Substance P & $\begin{array}{l}\text { forward, } 5^{\prime} \text {-CAGAGGAAATCGGTGCCAAC- } 3^{\prime} \\
\text { reverse, } 5^{\prime} \text {-CTGCTGAGGCTTGGGTCTTC- } 3^{\prime}\end{array}$ \\
\hline CGRP & $\begin{array}{l}\text { forward, 5'-CTTTCCTGGTTGTCAGCATCTT-3' } \\
\text { reverse, } 5^{\prime} \text {-AAGTTGTCCTTCACCACACCTC-3' }\end{array}$ \\
\hline IL-1 $\beta$ & $\begin{array}{l}\text { forward, 5'-TGATGACGACCTGCTAGTGTG-3' } \\
\text { reverse, } 5^{\prime} \text { - TCCATTGAGGTG- GAG AGCTT-3' }\end{array}$ \\
\hline IL-6 & 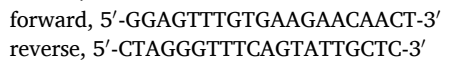 \\
\hline TNF- $\alpha$ & $\begin{array}{l}\text { forward, } 5^{\prime} \text { - ATGAGCACAGAAAGCATGATC- }{ }^{\prime} \\
\text { reverse, } 5^{\prime} \text {-TACAGGCTTGTCACTCGAATT- } 3^{\prime}\end{array}$ \\
\hline$\beta$-actin & $\begin{array}{l}\text { forward, } 5^{\prime} \text {-CGTTGACATCCGTAAAGACCTC- }{ }^{\prime} \\
\text { reverse, } 5^{\prime} \text {-TAGGAGCCA GGGCAGTAATCT- } 3^{\prime}\end{array}$ \\
\hline
\end{tabular}




\subsection{Statistical analysis}

One-way or two-way ANOVA tests were used for statistical analysis, followed by Dunnett's posthoc or bonferroni test, using GraphPad prism software. A $P$-value of $\leq 0.05$ was considered statistically significant.

\section{Results}

\subsection{Evaluation of anti-nociceptive activities of $3 H F$}

\subsubsection{Acetic acid-induced writhing model}

In this study, we found a significant decline in the number of aceticacid induced writhes, which indicate an increased \%-inhibition of pain in mice treated with diclofenac at a dose of $50 \mathrm{mg} / \mathrm{kg}(* * * \mathrm{p}<0.001)$, $3 \mathrm{HF}$ at doses of $25 \mathrm{mg} / \mathrm{kg}$ ( $* \mathrm{p}<0.05), 50 \mathrm{mg} / \mathrm{kg}(* * \mathrm{p}<0.01)$, and 75 $\mathrm{mg} / \mathrm{kg}(* * * \mathrm{p}<0.001)$ as compared to the vehicle-treated mice (Fig. 2).

\subsubsection{Hot plate test}

Mice treated with Tramadol $(30 \mathrm{mg} / \mathrm{kg}$ ) and $3 \mathrm{HF}(75 \mathrm{mg} / \mathrm{kg})$ exhibited a significant increase in protection (\%) from pain induced by thermal stimuli at 30,60 , and 90 min intervals $(* * * \mathrm{p}<0.001)$. Likewise the $3 \mathrm{HF}$ at doses of 25 and $50 \mathrm{mg} / \mathrm{kg}$ also showed significant percent protection from pain at all intervals (*p $<0.05, * * p<0.01$ ) (Fig. 3).
3.1.3. Effect of naloxone on the anti-nociceptive potential of $3 H \mathrm{HF}$ using hot plate model

The antagonizing effect of Naloxone on Tramadol and 3HF's analgesic activities in mice were investigated in the hotplate test. Results have shown in Fig. 4 that the Naloxone $(1 \mathrm{mg} / \mathrm{kg}$ ) antagonized the antinociceptive potential of Tramadol and 3HF significantly (*p $<0.05$, ${ }^{* *} \mathrm{p}$ $\left.<0.01,{ }^{* * *} \mathrm{p}<0.001\right)$ at $30-90 \mathrm{~min}$ intervals.

\subsection{Anti-inflammatory activity of $3 H F$}

In the carrageenan-induced paw edema test, $\mathbf{3 H F}$ attenuated exaggeration in paw-edema at concentrations of 25,50 , and $75 \mathrm{mg} / \mathrm{kg}$, observed at $1 \mathrm{~h}(P<0.05, P<0.001), 3 \mathrm{~h}(P<0.05, P<0.01, P<$ $0.001)$, and $5 \mathrm{~h}(P<0.01)$ after carrageenan administration. However, the standard drug diclofenac $(50 \mathrm{mg} / \mathrm{kg}$ ) was effective in mitigating the escalation of inflammation associated with carrageenan $(P<0.001)$ (Table 3).

In the histamine-induced paw edema test, 3HF reduced inflammation at tested doses for $1-5 \mathrm{~h}$ experiment $(P<0.05, P<0.01, P<$ 0.001 ). At the dose of $25 \mathrm{mg} / \mathrm{kg}$, 3HF alleviate paw edema for $1-3 \mathrm{~h}$ more efficiently $(P<0.05)$. Similarly, $3 \mathrm{HF}$ at doses of 50 and $75 \mathrm{mg} / \mathrm{kg}$, effectively reduced paw edema volume during 1-5 h experiment significantly $(P<0.01, P<0.001)$. Chlorpheniramine $(10 \mathrm{mg} / \mathrm{kg})$ was used as a standard drug, reduced paw edema volume at 1,3 , and $5 \mathrm{~h}$

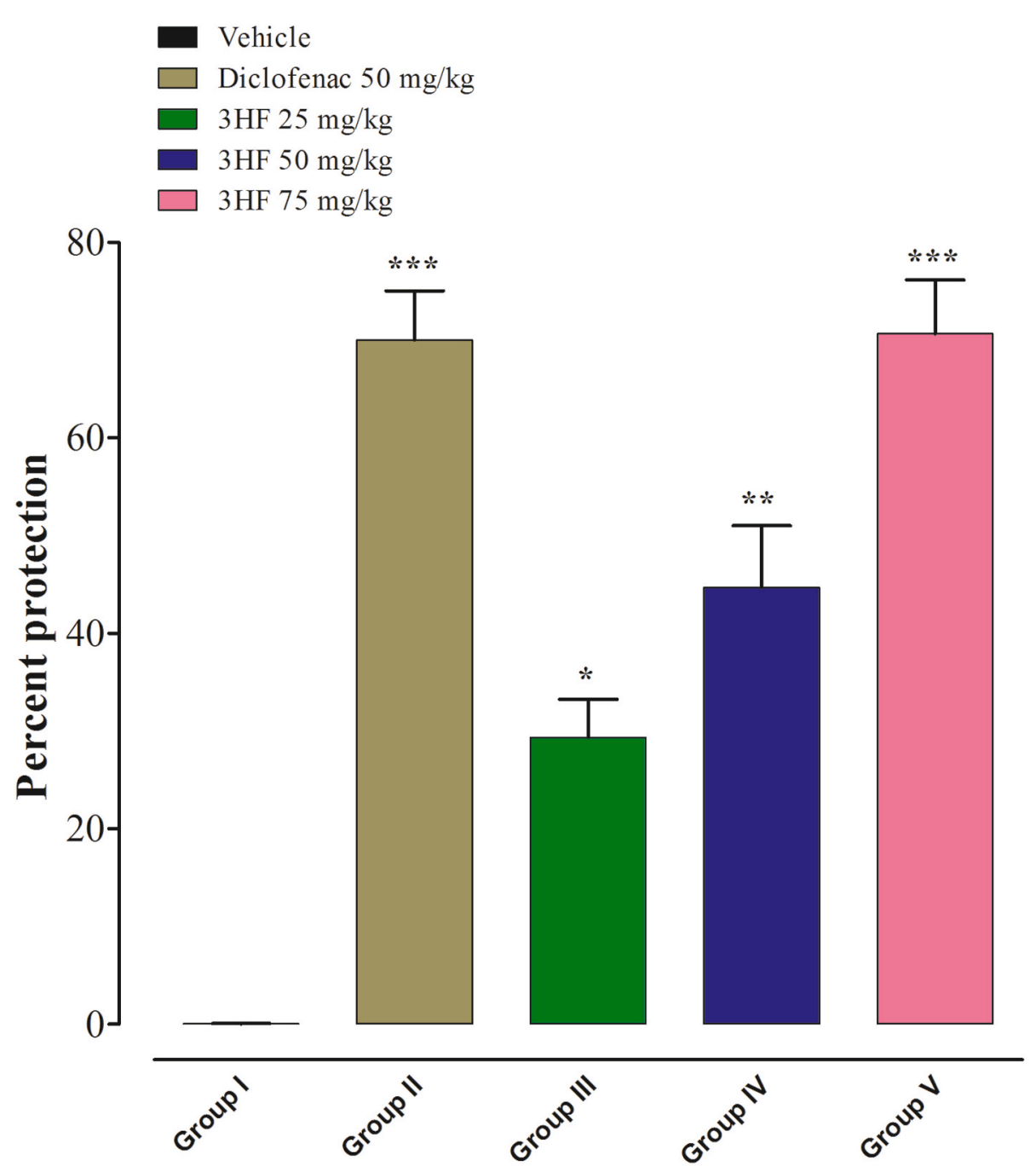

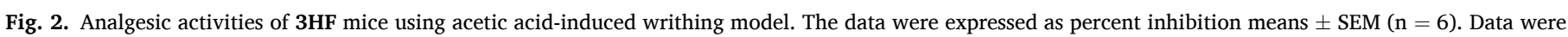

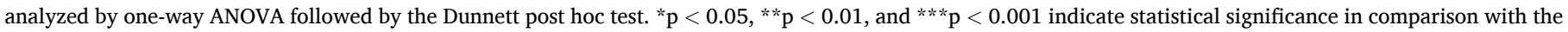
vehicle-treated group. 


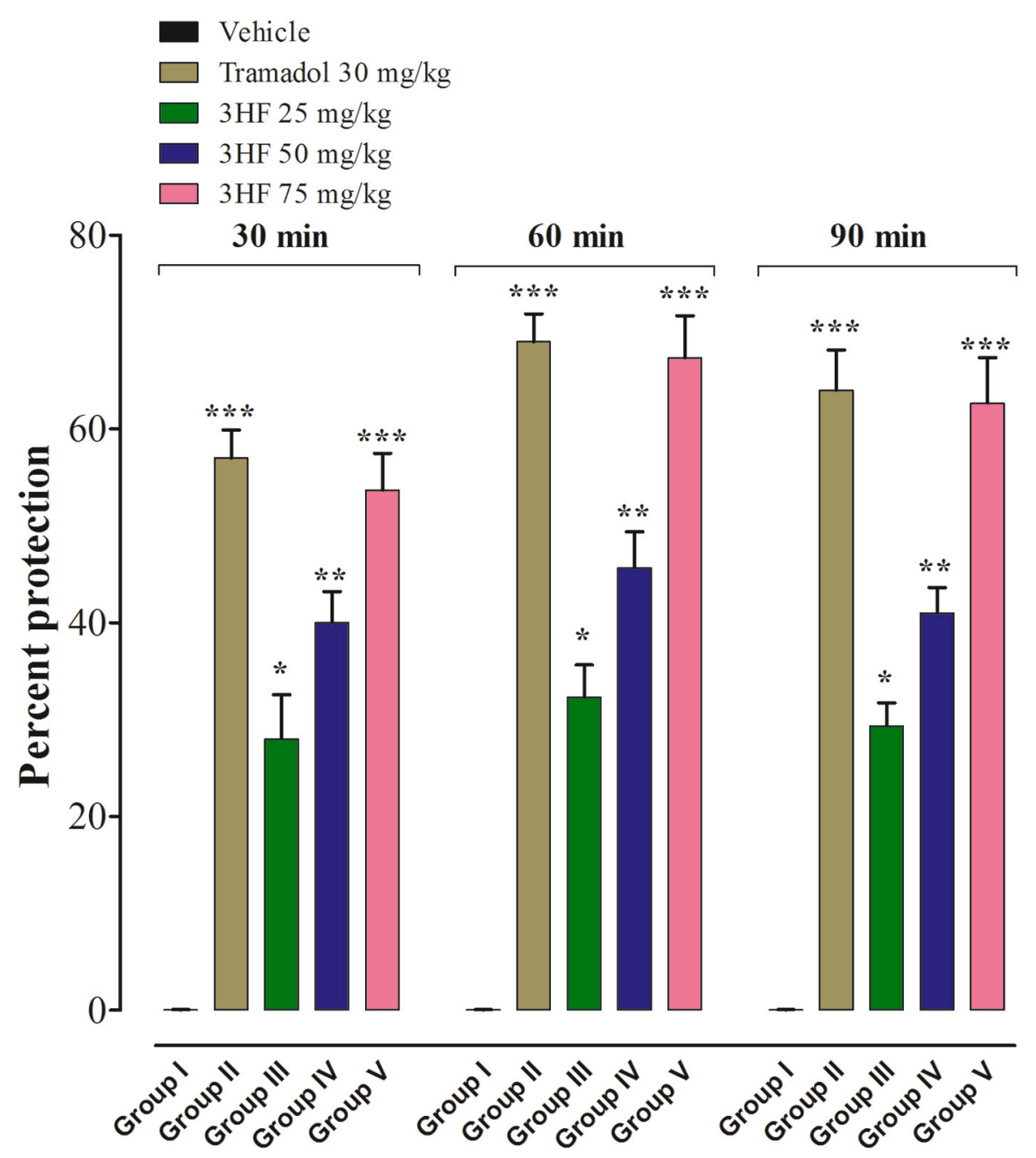

Fig. 3. Effect of $3 \mathrm{HF}$ at doses of 25,50 , and $75 \mathrm{mg} / \mathrm{kg}$ on thermally induced nociception in mice in Hot plate test. Data were analyzed by one-way ANOVA followed by Dunnett posthoc. The bar expressed percent protection means \pm SEM $(n=6)$. ${ }^{*} \mathrm{p}<0.05$, ${ }^{* *} \mathrm{p}<0.01$, and ${ }^{* * *} \mathrm{p}<0.001$ indicates statistical significance in comparison with the vehicle-treated group.

intervals significantly $(P<0.001)$ (Table 3).

In the serotonin-induced paw edema test, 3 HF was effective at doses of $25-75 \mathrm{mg} / \mathrm{kg}$ in the inhibition of serotonin-induced inflammation during $1-5$ h experiment $(P<0.05, P<0.01, P<0.001)$. Mianserin $(1$ $\mathrm{mg} / \mathrm{kg}$ ) was used as a standard drug, reduced paw edema at all intervals significantly $(P<0.001)$ (Table 3$)$.

\subsection{Effects of $3 H F$ on tactile allodynia}

The neuropathic allodynia was produced by intraperitoneal administration of paclitaxel at a dose of $4 \mathrm{mg} / \mathrm{kg}$ for 4 alternate days, reduced paw withdrawal threshold (PWT) on days 4,6 , and 8 significantly as compared to vehicle-treated group $(P<0.01, P<0.001)$. The paclitaxelinduced allodynia was significantly reduced by $3 \mathrm{HF}$ treatment [time= $(\mathrm{F}(4,90)=18.6, P<0.0001$, treatment $=(\mathrm{F}(5,90)=30.5, P<0.0001$, interaction $=(\mathrm{F}(20,90)=4.32, P<0.0001)]$. Treatment with the $3 \mathrm{HF}$ at a dose of $25 \mathrm{mg} / \mathrm{kg}$ showed a significant increase in PWT $(P<0.05)$ on day 8 . Whereas at the dose of $50 \mathrm{mg} / \mathrm{kg}$ increased the PWT on days 6 and 8 significantly $(P<0.01)$. Moreover, 3HF $(75 \mathrm{mg} / \mathrm{kg})$ inhibited the reduction in the withdrawal-threshold on days 6 and $8(P<0.001)$. The standard Gabapentine displayed a significant increase in threshold $(P<$ 0.0001) (Fig. 5).

\subsection{Effects of 3HF on cold allodynia}

Cold allodynia was induced in rats after repeated administration of paclitaxel, exhibited increase paw withdrawal duration (PWD) in comparison with vehicle-treated group $(P<0.0001)$. Treatment with $\mathbf{3 H F}$ significantly reduced the paclitaxel-induced cold allodynia in rats [time $=(\mathrm{F}(4,90)=39.7, P<0.0001$, treatment $=(\mathrm{F}(5,90)=42.5, P<$ 0.0001 , interaction $=(\mathrm{F}(20,90)=3.88, P<0.0001)]$. The $3 \mathrm{HF}(25 \mathrm{mg} /$ $\mathrm{kg})$ treated group exhibited a significant decrease in PWD $(P<0.05)$ on day 8 . The $3 \mathrm{HF}$ at the dose of $50 \mathrm{mg} / \mathrm{kg}$ caused a significant decrease in PWD on days 4,6 , and $8(P<0.05, P<0.01, P<0.001)$. While, 3 HF $(75 \mathrm{mg} / \mathrm{kg})$ treated group displayed a significant decline in PWD $(P<$ $0.05, P<0.001)$. Likewise, the standard Gabapentine exhibited a significant decrease in PWD $(P<0.0001)$ (Fig. 6).

\subsection{Effects of $3 H F$ on thermal hyperalgesia}

Repeated Paclitaxel administration caused significant changes in thermal nociceptive perception, indicated by decreased paw withdrawal latency $(\mathrm{PWL})$ in paclitaxel treated group as compared to vehicle-treated group $(P<0.05, P<0.01)$. The paclitaxel therapy associated thermal hyperalgesia was significantly reduced by $3 \mathrm{HF}$ treatment $[$ time $=(\mathrm{F}(4$, $60)=3.75, P<0.0087$, treatment $=(\mathrm{F}(5,60)=8.39, P<0.0001$, interaction $=(\mathrm{F}(20,60)=1.14, P<0.3360)]$. Treatment with 3 HF 


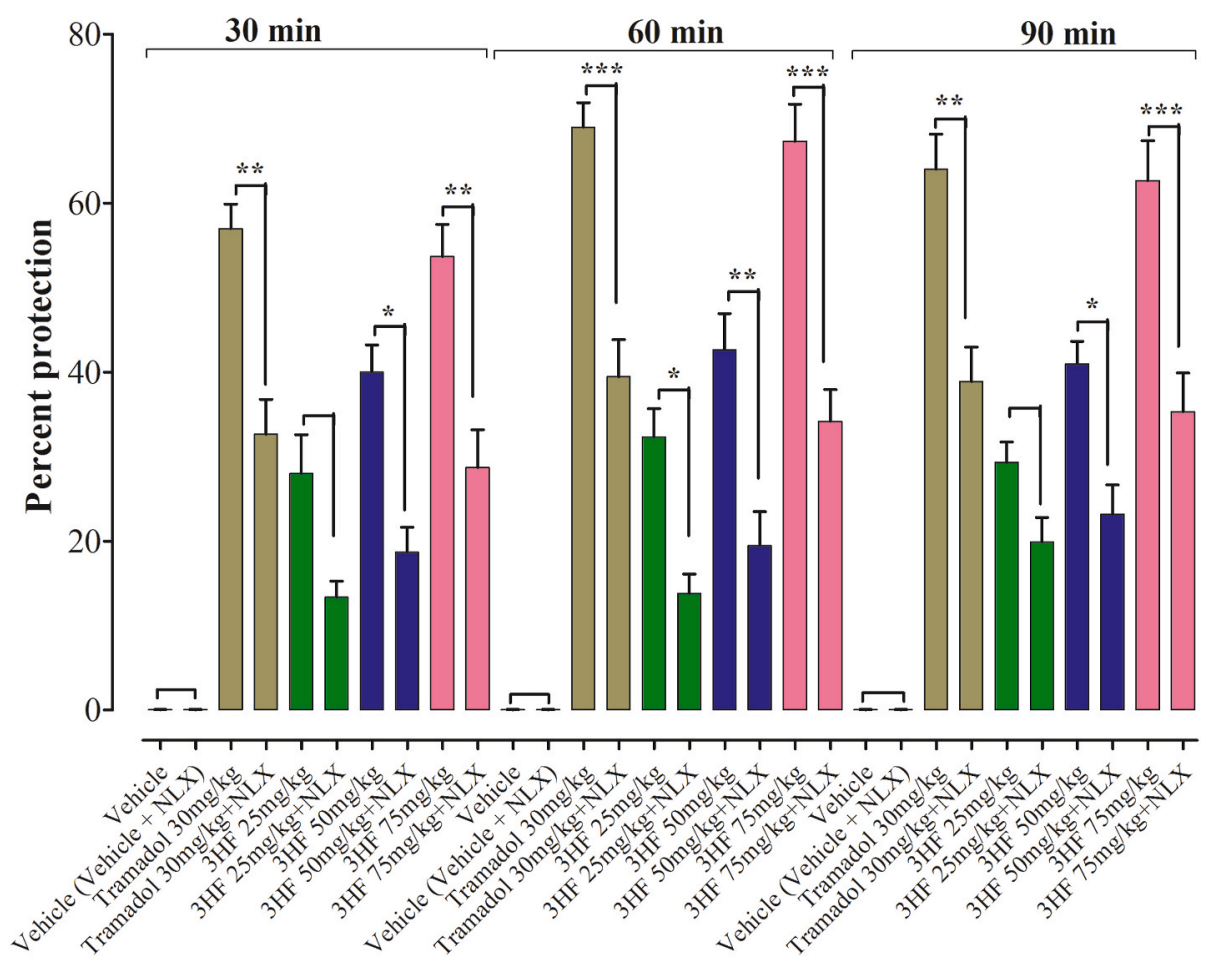

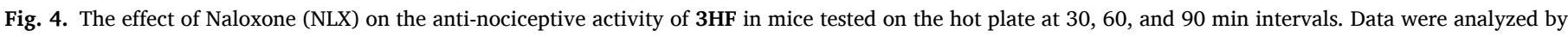

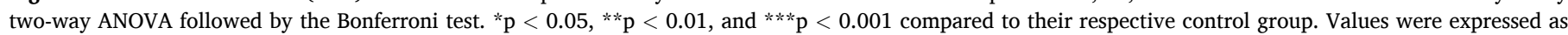
$\%$-protection means \pm SEM $(n=6)$.

Table 3

Effect of 3-hydroxy flavone (3HF) on phlogestic agents induced inflammation.

\begin{tabular}{|c|c|c|c|c|c|}
\hline \multirow[t]{2}{*}{ Phlogestic agent } & \multirow[t]{2}{*}{ Treatment } & \multirow[t]{2}{*}{ Dose } & \multirow{2}{*}{$\frac{1 \mathrm{~h}}{\text { Inhibitions (\%) }}$} & \multirow{2}{*}{$\frac{3 \mathrm{~h}}{\text { Inhibitions (\%) }}$} & \multirow{2}{*}{$\frac{5 \mathrm{~h}}{\text { Inhibitions (\%) }}$} \\
\hline & & & & & \\
\hline \multirow[t]{5}{*}{ Carrageenan } & Vehicle + Carrag & $10 \mathrm{ml} / \mathrm{kg}$ & $12.24 \pm 3.890$ & $9.97 \pm 2.572$ & $09.58 \pm 4.932$ \\
\hline & Diclofenac + Carrag & $50 \mathrm{mg} / \mathrm{kg}$ & $77.53 \pm 7.731^{* * *}$ & $64.23 \pm 5.084 * * *$ & $55.56 \pm 7.094 * * *$ \\
\hline & $3 \mathrm{HF}+$ Carrag & $25 \mathrm{mg} / \mathrm{kg}$ & $50.73 \pm 9.652^{* *}$ & $39.35 \pm 8.926^{*}$ & $28.08 \pm 10.876$ \\
\hline & & $50 \mathrm{mg} / \mathrm{kg}$ & $63.25 \pm 8.324^{* * *}$ & $52.78 \pm 5.768^{* *}$ & $43.06 \pm 5.765^{* *}$ \\
\hline & & $75 \mathrm{mg} / \mathrm{kg}$ & $72.65 \pm 5.649^{* * *}$ & $63.09 \pm 4.089^{* * *}$ & $50.84 \pm 9.087^{* *}$ \\
\hline \multirow[t]{5}{*}{ Histamine } & Vehicle + His & $10 \mathrm{ml} / \mathrm{kg}$ & $08.37 \pm 4.251$ & $06.08 \pm 2.875$ & $07.83 \pm 1.705$ \\
\hline & Chlorphinarmin + His & $10 \mathrm{mg} / \mathrm{kg}$ & $79.95 \pm 6.984 * * *$ & $62.50 \pm 7.409 * * *$ & $53.75 \pm 6.914^{* * *}$ \\
\hline & $3 \mathrm{HF}+\mathrm{His}$ & $25 \mathrm{mg} / \mathrm{kg}$ & $45.43 \pm 7.309^{* *}$ & $35.79 \pm 5.907^{*}$ & $26.05 \pm 4.359$ \\
\hline & & $50 \mathrm{mg} / \mathrm{kg}$ & $57.32 \pm 8.237^{* * *}$ & $44.95 \pm 7.946^{* *}$ & $35.06 \pm 6.901 * *$ \\
\hline & & $75 \mathrm{mg} / \mathrm{kg}$ & $69.82 \pm 3.594 * * *$ & $58.15 \pm 8.965^{* * *}$ & $45.98 \pm 3.802 * *$ \\
\hline \multirow[t]{5}{*}{ Serotonin } & Vehicle + Ser & $10 \mathrm{ml} / \mathrm{kg}$ & $05.27 \pm 4.568$ & $4.83 \pm 2.790$ & $4.97 \pm 2.371$ \\
\hline & Mianserin + Ser & $1 \mathrm{mg} / \mathrm{kg}$ & $82.62 \pm 3.962^{* * *}$ & $65.27 \pm 5.982^{* * *}$ & $56.63 \pm 7.045^{* * *}$ \\
\hline & $3 \mathrm{HF}+\mathrm{Ser}$ & $25 \mathrm{mg} / \mathrm{kg}$ & $48.05 \pm 7.859 * *$ & $37.27 \pm 5.309^{*}$ & $28.92 \pm 3.701$ \\
\hline & & $50 \mathrm{mg} / \mathrm{kg}$ & $59.64 \pm 5.967^{* * *}$ & $47.15 \pm 5.907^{* *}$ & $38.82 \pm 6.172^{* *}$ \\
\hline & & $75 \mathrm{mg} / \mathrm{kg}$ & $75.28 \pm 5.637^{* * *}$ & $63.08 \pm 4.049^{* * *}$ & $51.81 \pm 6.903^{* * *}$ \\
\hline
\end{tabular}

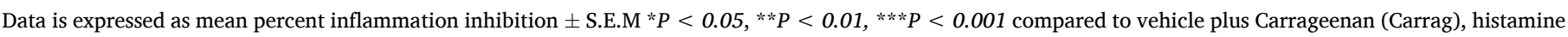
(His) or serotonin (Ser) treated group, one way ANOVA followed by Dunnett's post hoc test.

ameliorated the neuropathic thermal hyperalgesia significantly $(P<$ 0.05, $P<0.01$ ) as compared to paclitaxel-treated group (Fig. 7).

\subsection{Effects of $3 H F$ on tail hyperalgesia}

The anti-nociceptive tail immersion test was performed to observe the tail withdrawal response latency (TWL). Tail withdrawal reflexes indicate central nociception. Animals treated with paclitaxel showed a decrease in TWL as compared to the control group $(P<0.05, P<0.01$, $P<0.001)$. The 3 HF $(25-75 \mathrm{mg} / \mathrm{kg})$ and gabapentine treatment prolonged the TWL $(P<0.05, P<0.01, P<0.001)$ (Fig. 8).

\subsection{Effects of $3 H F$ on tail cold hyperalgesia}

To assess the cold anti-hyperalgesia properties of 3HF, tail immersion test in cold water was performed. Paclitaxel-treated rats showed a decrease in TWL as compared to the vehicle-treated group, indicating enhanced cold hyperalgesia in rats. 3HF treated animals exhibited an increase in TWL dose-dependently as compared to vehicle-treated animals $(P<0.05, P<0.01, P<0.001)$, indicating the protective effect of 3HF against cold hyperalgesia. Likewise, Gabapentine also displayed an increase in TWL $(P<0.001)$ (Fig. 9).

\subsection{Effects of $3 H F$ on motor activity of animals}

Rotarod test was performed to assess the undesirable effects of drug 


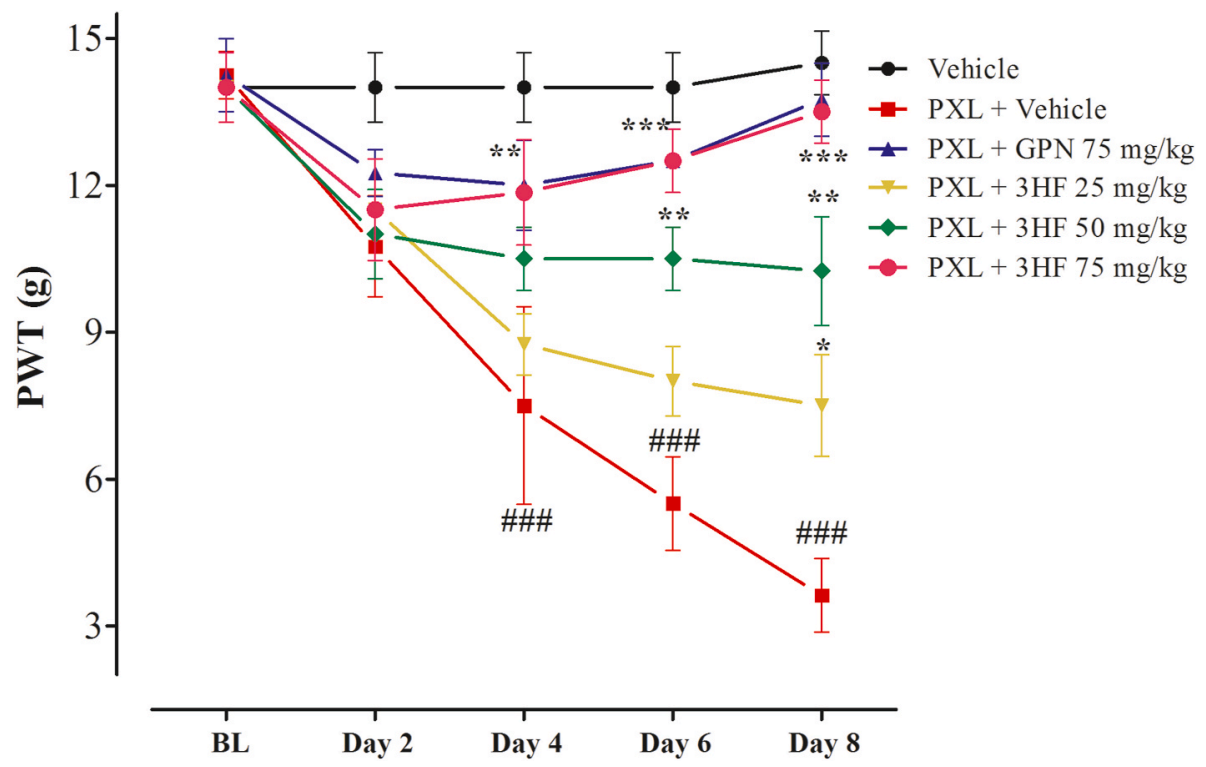

Fig. 5. Effect of $3 \mathrm{HF}$ on paclitaxel associated tactile allodynia. The symbol indicates mean PWT (g) \pm SEM. $* P<0.05$, $* * P<0.01$, $* * * P<0.001$ compared to paclitaxel + vehicle-treated group. ${ }^{\# \# \#} P<0.001$ compared to the vehicle-treated group. Two-way ANOVA followed by Bonferroni test, $\mathrm{n}=8$ rats/group.

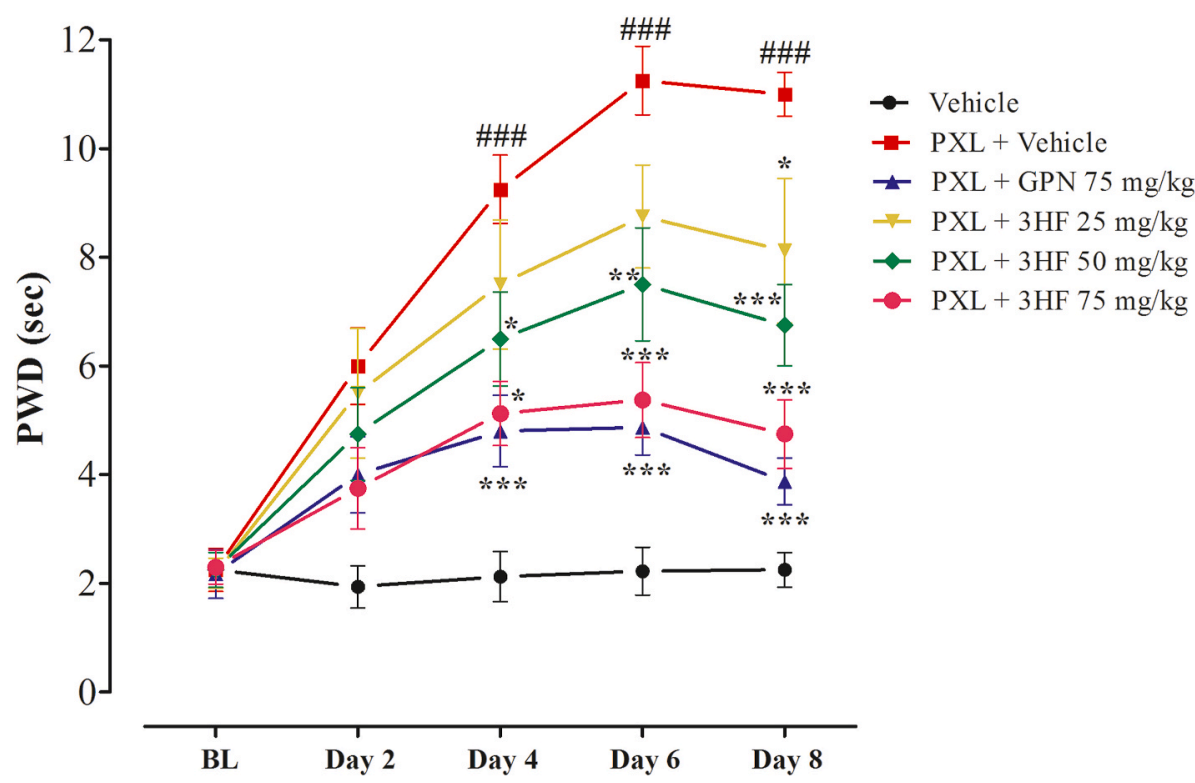

Fig. 6. Effect of $3 \mathrm{HF}$ on paclitaxel-induced cold allodynia. The symbol indicates mean PWD (s) \pm SEM. $* P<0.05$, $* * P<0.01$, ${ }^{* * *} P<0.001$ compared to paclitaxel

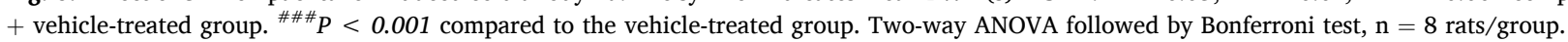

treatments on muscles and general body weakness. Treatment with standard gabapentin was linked with motor coordination impairment as evident by a decline in latency to fall in the gabapentin + paclitaxel treated animals. A significant effect on latency to fall in rotarod was observed $[$ time $=(\mathrm{F}(4,90)=3.97, P<0.0052$, treatment $=(\mathrm{F}(5,90)=$ $31.6, P<0.0001$, interaction $=(\mathrm{F}(20,90)=2.37, P<0.0030)]$. There was no motor coordination deficit observed in $3 \mathbf{H F}$ treated animals as compared to gabapentine treated group (Fig. 10).

3.9. Effects of 3HF on mRNA expression of TNF- $\alpha, I L-1 \beta, I L-6, C G R P$, and substance $P$ in the spinal cord

To assess the anti-inflammatory and anti-neuropathic pain activities of 3HF, the expression of different cytokines, CGRP, and Substance P (SP) in the spinal cord was investigated through RT-PCR. Paclitaxel treated animals displayed an increase in the expression of these mediators as compared to the vehicle-treated animals $(P<0.001)$. While 3HF and gabapentin treated animals depicted reduced mRNA expression of these mediators in the spinal cord as compared to the vehicle treated animals $(P<0.001)$ (Fig. 11).

\subsection{Molecular docking studies}

In order to rationalize the binding mechanism of $3 \mathbf{H F}$, the compound was subjected to molecular docking. For this purpose, initially, potential drug targets were searched via a systematic literature review (Kaur and Muthuraman, 2020). In our experiments, 3HF reduced the mRNA expression of several mediators including TNF- $\alpha$, IL-1 $\beta$, IL-6, CGRP, and Substance $\mathrm{P}$ in the spinal cord. Several studies have demonstrated the role of NF- $\mathrm{KB}$ in the underlying mechanism of inflammatory 


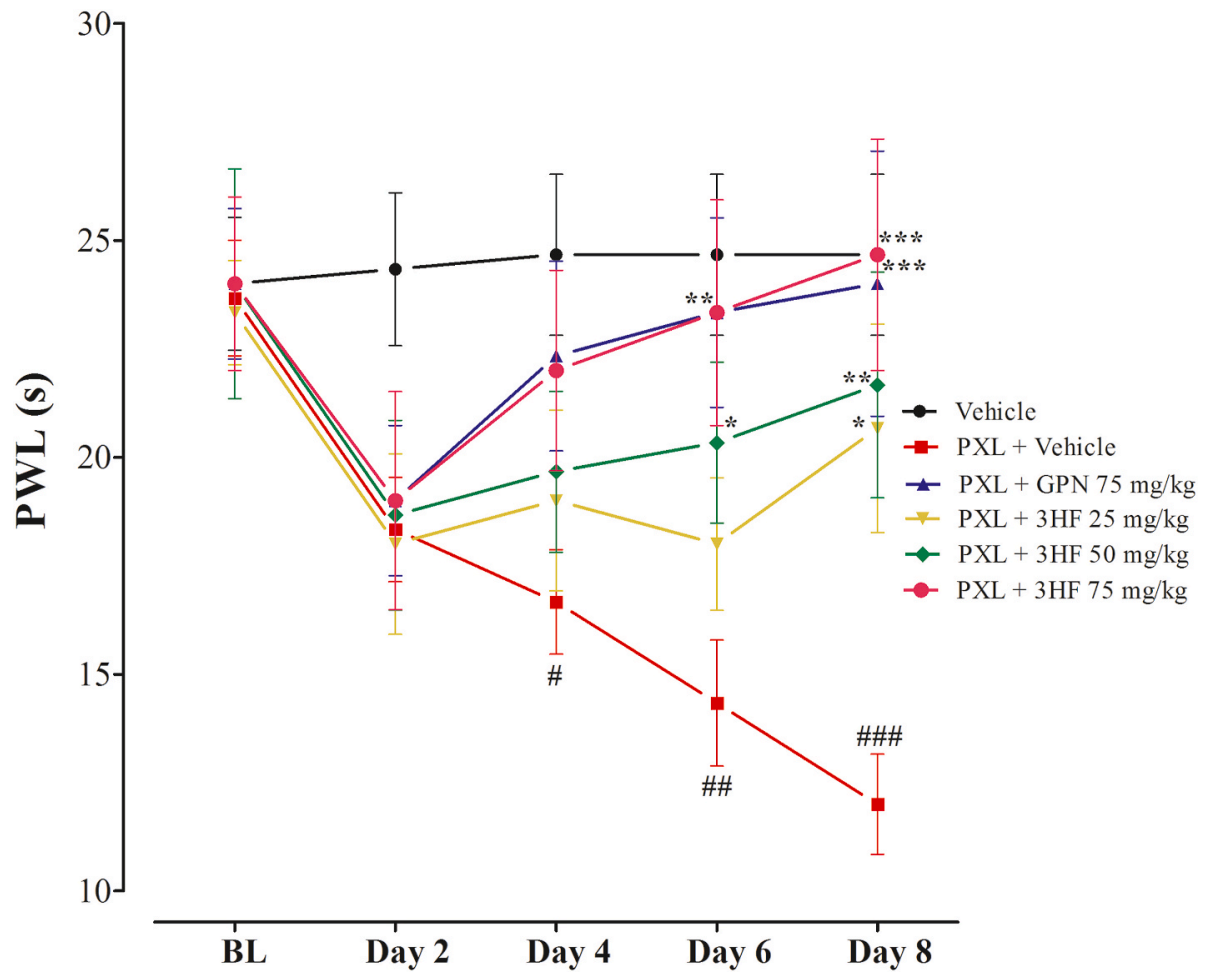

Fig. 7. Effect of $3 \mathrm{HF}$ on paclitaxel-induced thermal hyperalgesia in rats. The bar represents mean latency time in $\mathrm{s} \pm \mathrm{SEM}$. $* P<0.05$, *** $P<0.01$, **** $P<0.001$ compared to paclitaxel + vehicle-treated group. ${ }^{\#} P<0.05,{ }^{\# \#} P<0.01$, ${ }^{\# \#} P<0.001$ compared to the vehicle-treated group. . Two-way ANOVA followed by Bonferroni test, $\mathrm{n}=8$ rats/group.

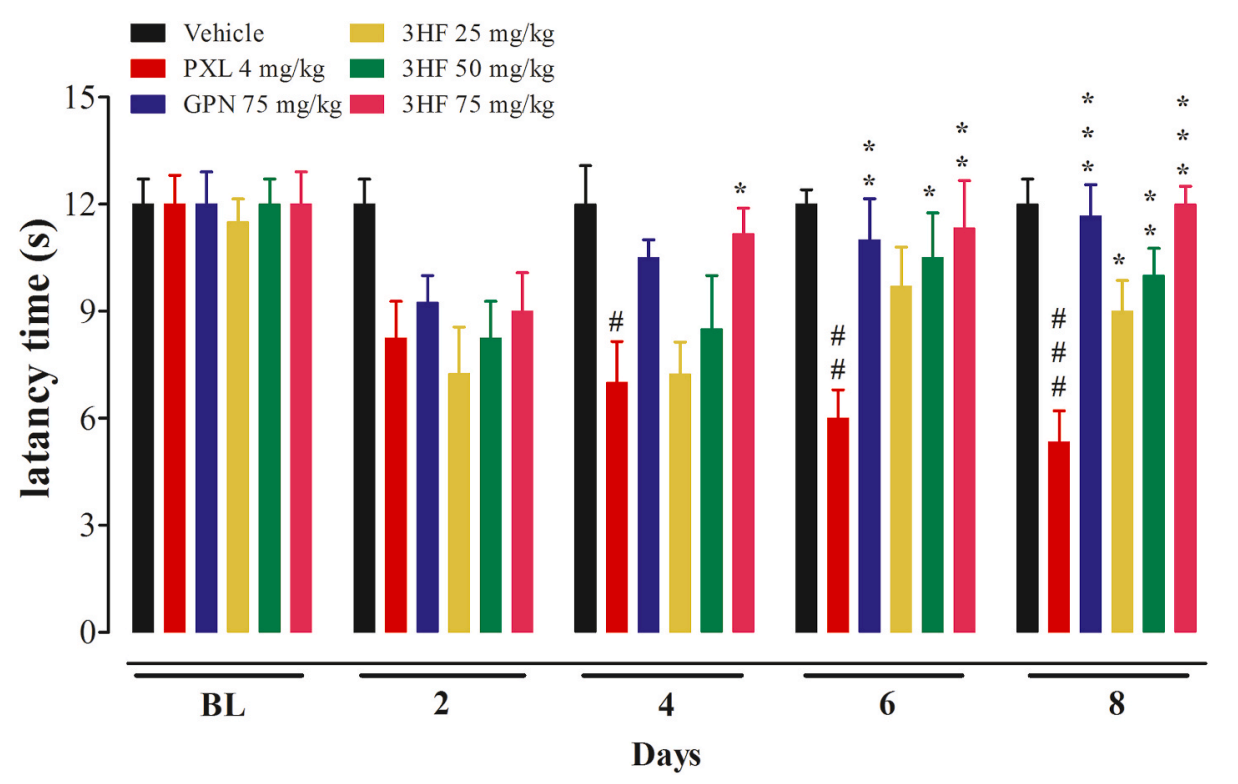

Fig. 8. Effect of 3HF on paclitaxel-induced tail heat-hyperalgesia in rats. The bar represents mean latency time in $\mathrm{s} \pm \mathrm{SEM}$. ${ }^{*} P<0.05$, ${ }^{* *} P<0.01,{ }^{* * *} P<0.001$, compared to paclitaxel + vehicle-treated group. ${ }^{\#} P<0.05$, ${ }^{\# \#} P<0.01$, ${ }^{\# \# \#} P<0.001$ compared to the vehicle-treated group. One-way ANOVA followed by Dunnett's posthoc test, $\mathrm{n}=8$ rats/group.

degenerative and neuropathic pain processes (Ahmed et al., 2019). Therefore, NF- $\mathrm{KB}$ was selected as a potential biological target for the docking of 3HF. Moreover, Substance P and CGRP are involved in nerve injury-induced neuropathic pain (Lee and Kim, 2007). CGRP exert its effects by binding with its receptor, so-called calcitonin receptor-like receptor (CALCRL), and a protein known as receptor activity-modifying protein (RAMP1), while substance $\mathrm{P}$ binds with its receptor known as neurokinin 1 receptor (NK1R) to mediate its biological effects. Both the receptors (CALCRL and NK1R) belong to the class of G-protein coupled receptors. CALCRL is composed of three subunits including RAMP1, calcitonin-like receptor (CLR) and receptor component protein (RCP). The CGRP binds with CALCRL in the complex. In order to produce an effect, CGRP and CALCRL coincide with RAMP1 where the ligand-binding domain of CGRP is located. However, the antagonist and SP binding sites on the NK1R are present in the extracellular loops and transmembrane regions of NK-1R. Therefore, 


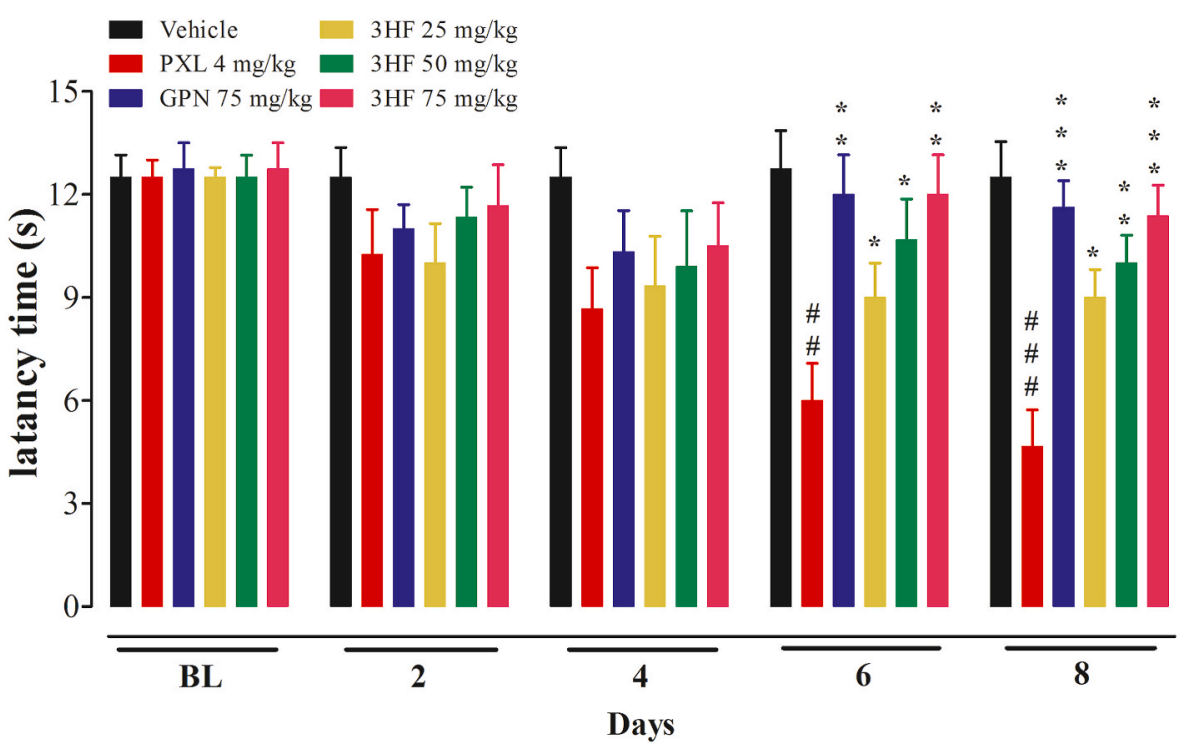

Fig. 9. Effect of $3 \mathrm{HF}$ on paclitaxel-induced tail cold-hyperalgesia in rats. The bar represents mean latency time in $\mathrm{s} \pm \mathrm{SEM}$. ${ }^{*} P<0.05$, $* * P<0.01$, ****$P<0.001$ compared to paclitaxel + vehicle-treated group. ${ }^{\# \#} P<0.01$, ${ }^{\# \# \# P}<0.001$ compared to the vehicle-treated group. One-way ANOVA followed by Dunnett's posthoc test, $\mathrm{n}=8$ rats/group.

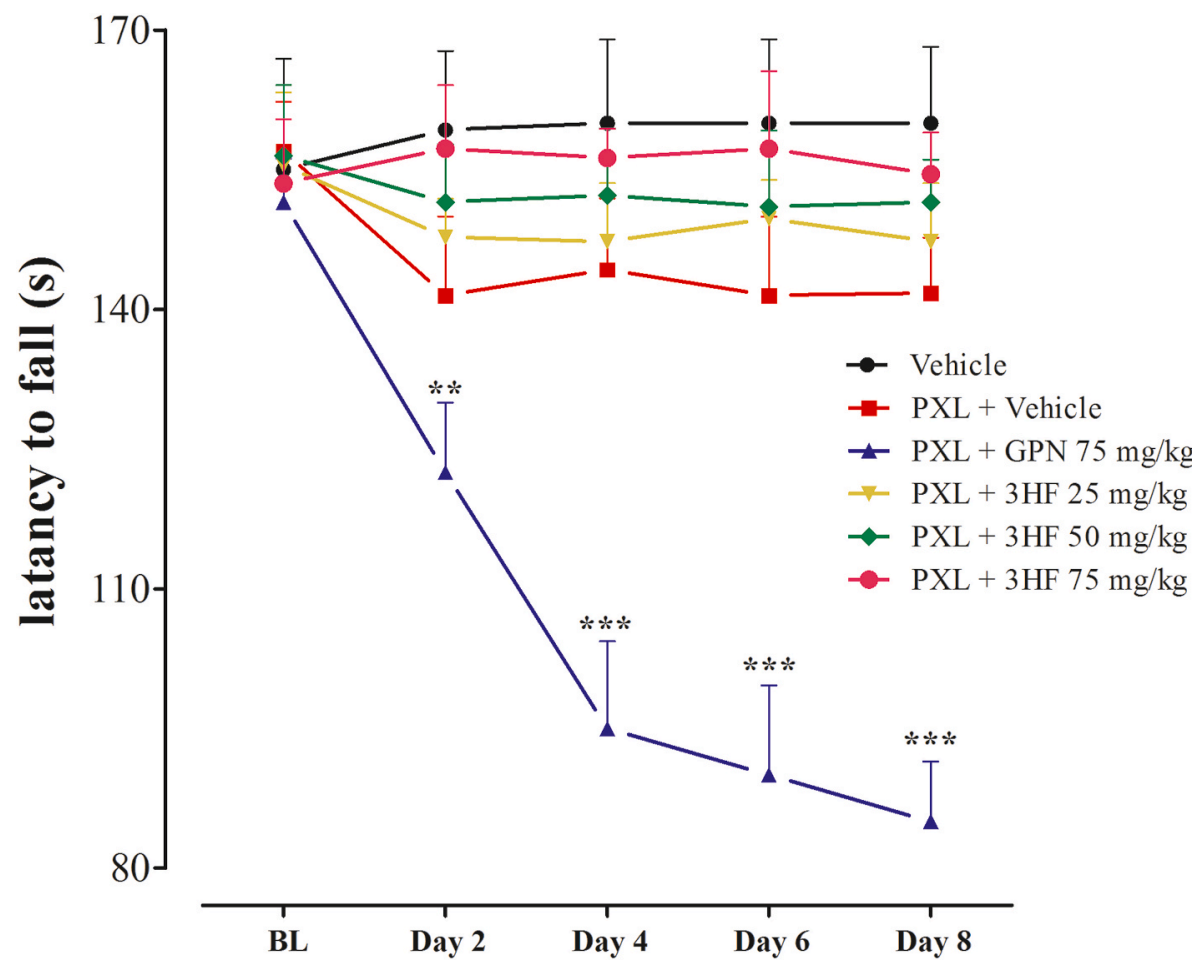

Fig. 10. Effect of $3 \mathrm{HF}$ on motor coordination in rats. The symbol indicates mean Latency to fall (s) \pm SEM. *P<0.05, **P<0.01, ***P $P<0.001$ compared to paclitaxel + vehicle-treated group. Two-way ANOVA followed by Bonferroni test, $\mathrm{n}=8$ rats/group.

3HF was also docked at the ligand-binding sites of the above-mentioned receptors.

When the flavone docked at the binding site of NF- $\mathrm{kB}$, and the $-\mathrm{OH}$ groups of 3HF mediated hydrogen bonds with the side chain of Lys 275 and two water molecules in the DNA binding hinge region of NF- $\mathrm{kB}$. The docking score of the compound was -4.58 , which is lesser than the docking scores of $3 \mathrm{HF}$ at Neurokinin 1 (NK1) and CGRP receptors. The binding interactions suggest that the 3HF has tendency to bind with the $\mathrm{NF}-\mathrm{\kappa B}$, however, docking scores indicates that the binding potential of test compound towards NF- $\mathrm{BB}$ is lesser than the NK-1 and CGRP receptors.

The docked orientation of 3HF at the NK-1 antagonist binding site revealed that the $3 \mathrm{HF}$ is nicely fitted at the binding groove and formed multiple hydrogen bonds with the surrounding residues including Lys181, Ile182 and Glu193. The flavone moiety of 3HF was stabilized by the hydrogen bonds donated by the backbone amino group and the side chain of Ile182 and Lys181, respectively. While the -OH group of 3HF donated a hydrogen bond to the side chain of Glu193. Moreover, 3HF depicted highly negative $(-5.36)$ docking score at NK-1 receptor, indicating that this receptor could be a potential target for 3HF. 

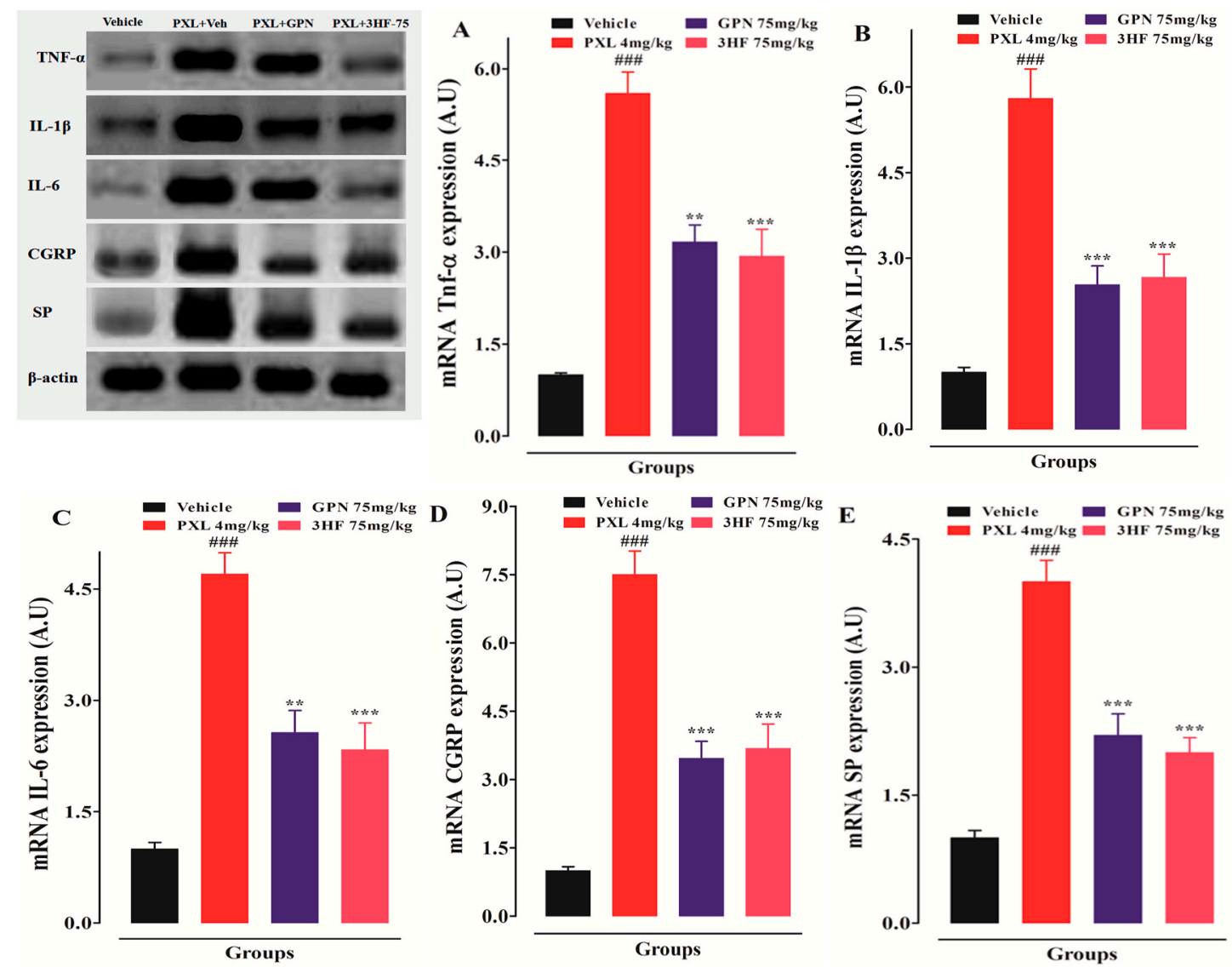

Fig. 11. Effect of 3HF on; TNF- $\alpha$ mRNA expression level (A), IL-1 $\beta$ mRNA expression level. (B), IL-6 expression level (C), CGRP mRNA expression level (D), and Substance P (SP) mRNA expression level in the spinal cord of rats (E). The symbol indicates mean expression in arbitrary unit (A.U) \pm SEM. ${ }^{*} P<0.05, * * P<0.01$,

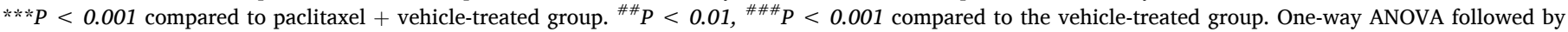
Dunnett's posthoc test, $\mathrm{n}=8$ rats/group.

3HF was docked at the ligand-binding site located between the extracellular and transmembrane regions of CALCRL and RAMP1. At the ligand-binding site of the CGRP receptor, the 3HF produced good binding interactions. The $-\mathrm{OH}$ and the ring oxygen of $3 \mathrm{HF}$ interacted with the Lys 40 and $\mathrm{Gln} 202$ of the receptor. Additionally, the side chain of Arg 18 of CGRP offered hydrophobic, particularly $\pi$-cation interaction to the ring moiety of the $3 \mathrm{HF}$. The docked orientation of the $3 \mathrm{HF}$ at the CGRP-CGRP receptor interface showed that 3HF exhibit excellent binding potential, however, the docking score suggests that the 3HF has a lesser binding affinity towards CGRP-R as compared to NK-1 receptor. The docking scores and binding interactions of the 3HF with the selected drug targets are tabulated in Table 4 . The docked view of the $3 \mathrm{HF}$ in the binding sites of the receptors is presented in Fig. 12.

\section{Discussion}

The anti-inflammatory activity of $\mathbf{3 H F}$ was tested in mice models of the different phlogistic agents (carrageenan, histamine, and serotonin) induced paw edema. The peripheral injection of carrageenan, histamine, and serotonin are associated with inflammation and pain (Naveed et al., 2019). Thus, the anti-inflammatory potential of $\mathbf{3 H F}$ was tested in carrageenan, histamine, and serotonin-induced inflammatory mice models where $\mathbf{3 H F}$ produced significant inhibitory effects (Table 3 ). The results indicate that $3 \mathbf{H F}$ can serve as a potential candidate to inhibit inflammatory responses in vivo. Whereas the anti-nociceptive activities 3HF was tested in writhing and hot plate tests. The finding of these activities indicated the anti-nociceptive potential of 3HF, which was further confirmed by naloxone antagonistic activity in hot plate test.

Table 4

The docking results of $3 \mathrm{HF}$ with the selected drug targets.

\begin{tabular}{|c|c|c|c|c|c|c|c|}
\hline \multirow[t]{2}{*}{ S. No. } & \multirow[t]{2}{*}{ Targets } & \multirow[t]{2}{*}{ PDB ID } & \multirow[t]{2}{*}{ Docking Score } & \multicolumn{4}{|c|}{ Binding Interactions } \\
\hline & & & & Ligand Atoms & Receptor Atoms & Interactions & Distance $(\AA)$ \\
\hline \multirow[t]{3}{*}{1} & \multirow[t]{3}{*}{ Nuclear factor kb } & \multirow[t]{3}{*}{$1 \mathrm{NFK}$} & \multirow[t]{3}{*}{-4.58} & $\mathrm{O} 3$ & NZ-LYS275 & HBA & 3.34 \\
\hline & & & & $\mathrm{O} 3$ & О-НОН377 & HBA & 2.89 \\
\hline & & & & $\mathrm{O} 2$ & O-HOH26 & HBA & 2.15 \\
\hline \multirow[t]{3}{*}{2} & \multirow[t]{3}{*}{ Substance P Receptor (Neurokinin 1 receptor) } & \multirow[t]{3}{*}{ 6HLP } & \multirow[t]{3}{*}{-5.36} & $\mathrm{O} 2$ & OE2-GLU193 & HBD & 2.79 \\
\hline & & & & $\mathrm{O} 3$ & NZ-LYS181 & HBA & 3.34 \\
\hline & & & & $\mathrm{O} 3$ & N-ILE182 & HBA & 3.23 \\
\hline \multirow[t]{3}{*}{3} & \multirow[t]{3}{*}{ CGRP Receptor } & \multirow[t]{3}{*}{$6 \mathrm{E} 3 \mathrm{Y}$} & \multirow[t]{3}{*}{-5.11} & $\mathrm{O} 1$ & NZ-LYS40 & HBA & 3.01 \\
\hline & & & & $\mathrm{O} 2$ & NE2-GLN202 & HBA & 3.15 \\
\hline & & & & 6-ring & NH2-ARG18 & $\pi-\pi$ & 3.48 \\
\hline
\end{tabular}

HBA = Hydrogen bond acceptor, HBD = Hydrogen bond donor. 

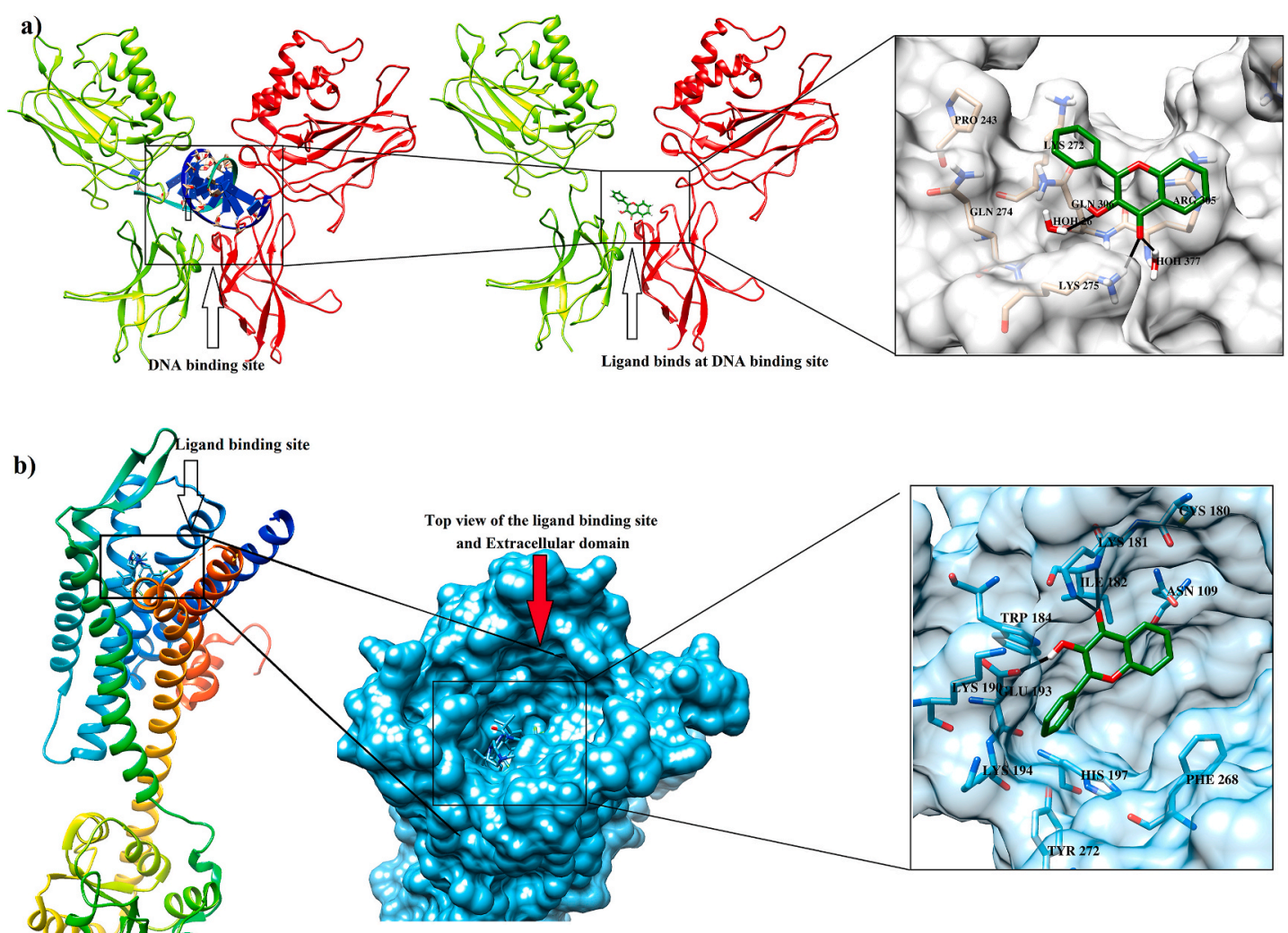

b)

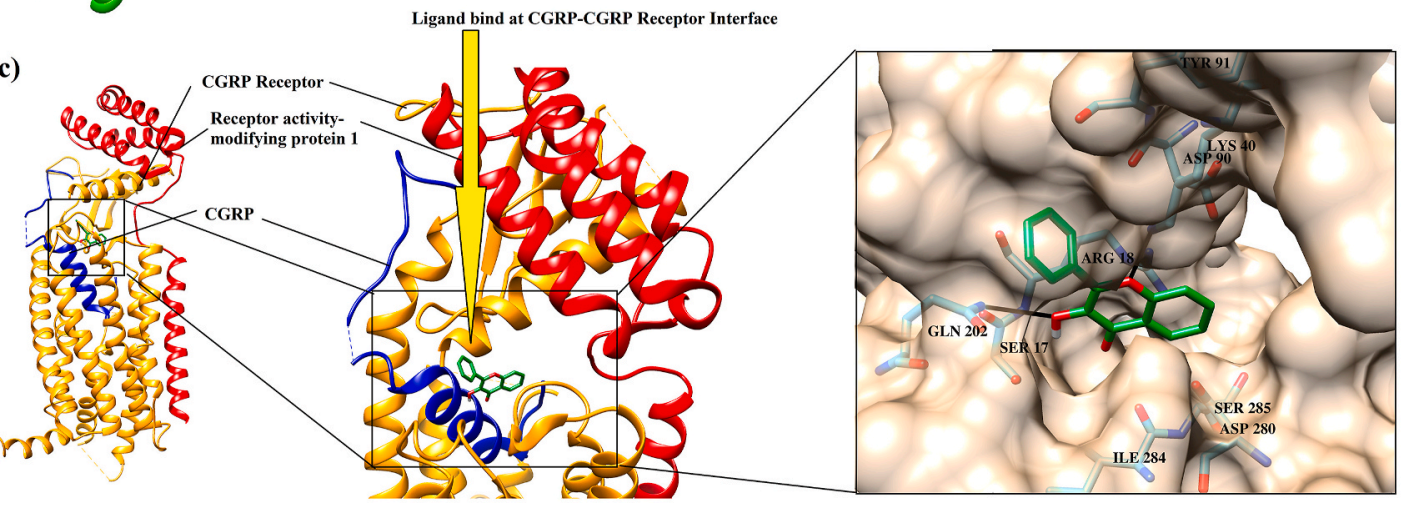

Fig. 12. The binding modes of the compounds in three different selected targets are shown (A). The docked view of 3HF is shown in the DNA binding cavity of NF- $\mathrm{kB}$ (shown in the green and red ribbon), DNA is shown in the blue ribbon. Ligand is presented in a green stick model. Hydrogen bonds are shown in black lines (B). The docked orientation of the ligand in the extracellular ligand-binding domain of the NK-1 receptor is shown in the figure. Ligand and H-bonds are shown in green stick and black lines, respectively (C). The binding mode of the ligand is shown in the CGRP receptor. CGRP receptor (gold ribbon) is presented in complex with CGRP (blue ribbon) and receptor activity modifying protein 1 (red ribbon). Ligand and H-bonds are depicted in green stick model and black lines, respectively.

The anti-neuropathic effect of $3 \mathbf{H F}$ was tested in rat's model of paclitaxel-induced peripheral neuropathy. Different neuropathic sensations like tactile and cold allodynia and heat-hyperalgesia were observed after the administration of paclitaxel. In connection to this study, effects of 3 HF were studied on the expression of the inflammatory cytokines (TNF- $\alpha$, IL-1 $\beta$, IL-6), CGRP, and Substance P in the spinal cord.

Pain management is crucially challenging specifically for patients suffering from chronic pain like neuropathic pain (Khan et al., 2016). Moreover, chemotherapy-induced-neuropathy is one of the major adverse effects of anti-cancer drugs which halts the effectiveness of existing cancer chemotherapy (Hur et al., 2019; Vitet et al., 2018). Paclitaxel-induced neuropathy is a well-known adverse effect in humans and rodents. Although, the onset of sign and symptoms of neuropathy depends on the accumulative dose, frequency, and time duration of the anticancer agent (Flatters and Bennett, 2004; Quasthoff and Hartung, 2002). Although, Paclitaxel is the most effective and commonly used chemotherapeutic agent for the treatment of solid tumors, produces peripheral neurotoxicity linked with sensory abnormalities and neuropathic pain during and after paclitaxel therapy (Flatters and Bennett, 2004). Paclitaxel causes tactile- and cold-allodynia, and heat hyperalgesia (Scripture et al., 2006). There is no effective treatment for chemotherapy-induced neuropathy. The gabapentinoids such as gabapentin are used to treat neuropathic pain, however, their therapeutic efficacy is limited due to the occurrence of severe side effects such as somnolence, dizziness, lethargy, ataxia, and convulsions (Colloca et al., 2017; Gilron et al., 2015). Gabapentin impairs motor coordination and balance after systemic administration (Ahmad et al., 2017b). In our findings, the test compound 3HF did not show any detectable motor 
coordination deficit and found to be advantageous over gabapentin as a neurotherapeutic agent (Fig. 7). Similarly, 3HF produced beneficial effects in intensity to that produced by gabapentin. Gabapentinoids are effective for the treatment of peripheral neuropathies in paclitaxel-treated cancer patients (Aghili et al., 2019).

Paclitaxel $(4 \mathrm{mg} / \mathrm{kg})$ was administered four times a week on alternate days $(1,3,5$, and 7$)$ to develop peripheral painful neuropathy. The pain behaviors were assessed by evaluating tactile allodynia, acetone induced cold allodynia, paw thermal hyperalgesia, tail hot and cold hyperalgesia on days $0,2,4,8$. In this study, $3 \mathrm{HF}(25,50$, and $75 \mathrm{mg} / \mathrm{kg})$ possibly altered the nociceptive threshold in the form of different pain parameters like PWT (g) (Fig. 5), PWD (s) (Fig. 6), paw thermal hyperalgesia (PWL) (Fig. 7), tail withdrawal latency in hot and cold conditions (Figs. 8 and 9), in a dose-dependent manner. The 3HF treated animals possessed a significant anti-allodynic effect (tactile and acetone induced allodynia) by exhibiting increased PWT (g) and decreased PWD (s). Also, 3HF treated group showed a greater anti-hyperalgesic effect, increase PWL (s), and TWL (s), as compared to the paclitaxel treated group. The finding of the study demonstrated the anti-neuropathic potential of 3HF is at the behavioral level. Therefore, the behavioral neurotherapeutic effect of $\mathbf{3 H F}$ was confirmed by investigating the effects of 3HF on the expression of key mediators of inflammation and pain such as cytokines (TNF- $\alpha$, IL-1 $\beta$, IL-6), CGRP and Substance P (Fig. 11).

Inflammatory cytokines including TNF- $\alpha$, IL-1 $\beta$, and IL- 6 play a vital role in dorsal root ganglia (DRG) and Spinal cord neuronal damage, involved in the nociceptive pathway sensitization (Ledeboer et al., 2007), and in painful neuropathy. Paclitaxel induces the expression of proinflammatory cytokines in the rat DRG and spinal cord (Pavao-de-Souza et al., 2012). In this study, paclitaxel treatment increased the level of proinflammatory cytokines in the spinal cord of rats. Several in vitro and in vivo studies revealed that proinflammatory cytokines contribute to the pathogenesis of pain (Khan et al., 2013). However, 3HF reduced the expression of these cytokines, therefore, 3HF may exert an antinociceptive effect by reducing cytokines level in the spinal cord.

In addition, the level of CGRP and Substance P was increased significantly in the superficial dorsal horn of paclitaxel treated rats. CGRP and Substance P are neurotransmitters involved in the pathogenesis of neuropathic pain. These neurotransmitters released in the spinal dorsal horn by primary sensory afferents neurons contribute to production of allodynia and hyperalgesia (Ma and Eisenach, 2003). Treatment with $3 \mathrm{HF}$ attenuated the increased level of CGRP and Substance P significantly as compared to the paclitaxel treated rats.

Structure based drug design is excelling the drug-discovery process and assists to study the mechanism of protein-ligand or drug-target binding (Halim et al., 2020; Ur Rehman et al., 2020). Therefore, the $3 \mathrm{HF}$ was docked at the binding interface of receptors of CGRP and substance $\mathrm{P}$, and NF- $\mathrm{KB}$ which is considered as the main mediator of inflammation. The 3HF showed excellent binding patterns with the entire selected drug target, however, binding potential for Substance P receptor was higher than the other targets.

\section{Conclusion}

In conclusion, the present study revealed that $\mathbf{3 H F}$ has antnociceptive, anti-inflammatory activity, and attenuative potential against paclitaxel-induced neuropathic painful conditions. The beneficial effect of 3HF appears to occur via several mechanisms; including the inhibition of induction of cytokines (TNF- $\alpha$, IL-1 $\beta$, IL-6), CGRP, and substance P. 3HF is beneficial because of lack of central motor incoordination adverse effects. Thus, our finding suggests that the $3 \mathrm{HF}$ might be a multi-targeted drug for the treatment of CIPN. In light of these results, 3HF could be developed for the management of CIPN. By molecular docking studies, it was elucidated that 3HF could inhibit the receptor of substance P effectively to execute its effect. However, more comprehensive studies are required to elucidate the detailed mechanistic role of the $3 \mathbf{H F}$ against neuropathic pain modalities.

\section{Declaration of competing interest}

The authors declare that they have no known competing financial interests or personal relationships that could have appeared to influence the work reported in this paper.

\section{Acknowledgments}

The authors thank the Department of Pharmacy, University of Peshawar for providing the necessary facilities for these research activities.

$\begin{array}{ll}\text { Abbreviations } \\ \text { 3HF } & \text { 3-Hydroxyflavone } \\ \text { SD } & \text { Sprague Dawley } \\ \text { CGRP } & \text { Calcitonin gene-related peptide } \\ \text { TNF } & \text { Tumor necrosis factor } \\ \text { IL } & \text { Interleukin } \\ \text { NF-KB } & \text { Nuclear factor kappa B } \\ \text { DRG } & \text { dorsal root ganglion } \\ \text { CIPN } & \text { Chemotherapeutic agent induced peripheral neuropathy } \\ \text { PWT } & \text { Paw withdrawal threshold } \\ \text { TWL } & \text { Tail withdrawal latency } \\ \text { PDB } & \text { Protein data bank } \\ \text { CALCRL } & \text { Calcitonin receptor-like receptor } \\ \text { RAMP1 } & \text { Receptor activity-modifying protein } \\ \text { RCP } & \text { Receptor component protein }\end{array}$

\section{Ethics approval}

The experimental procedures were approved by the departmental ethical committee of (Approval no. 12/EC-17/Pharm) and were performed following rules of the UK Animals (Scientific Procedures) Act 1986.

\section{Availability of data and materials}

All datasets on which the conclusions of the manuscript rely are presented in the paper.

\section{References}

Aghili, M., Zare, M., Mousavi, N., Ghalehtaki, R., Sotoudeh, S., Kalaghchi, B., Akrami, S., Esmati, E., 2019. Efficacy of gabapentin for the prevention of paclitaxel induced peripheral neuropathy: a randomized placebo controlled clinical trial. Breast J. 25, 226-231.

Ahmad, N., Subhan, F., Islam, N.U., Shahid, M., Rahman, F.U., Fawad, K., 2017a. A novel pregabalin functionalized salicylaldehyde derivative afforded prospective pain, inflammation, and pyrexia alleviating propensities. Arch. Pharmazie 350, e201600365.

Ahmad, N., Subhan, F., Islam, N.U., Shahid, M., Rahman, F.U., Sewell, R.D., 2017b. Gabapentin and its salicylaldehyde derivative alleviate allodynia and hypoalgesia in a cisplatin-induced neuropathic pain model. Eur. J. Pharmacol. 814, 302-312.

Ahmed, A.S., Berg, S., Alkass, K., Druid, H., Hart, D.A., Svensson, C.I., Kosek, E., 2019. NF-KB-Associated pain-related neuropeptide expression in patients with degenerative disc disease. Int. J. Mol. Sci. 20, 658.

Akbar, S., Subhan, F., Karim, N., Shahid, M., Ahmad, N., Ali, G., Mahmood, W., Fawad, K., 2016. 6-Methoxyflavanone attenuates mechanical allodynia and vulvodynia in the streptozotocin-induced diabetic neuropathic pain. Biomed. Pharmacother. 84, 962-971.

Ali, G., Subhan, F., Abbas, M., Zeb, J., Shahid, M., Sewell, R.D., 2015. A streptozotocininduced diabetic neuropathic pain model for static or dynamic mechanical allodynia and vulvodynia: validation using topical and systemic gabapentin. N. Schmied. Arch. Pharmacol. 388, 1129-1140.

Authier, N., Gillet, J.-P., Fialip, J., Eschalier, A., Coudore, F., 2003. An animal model of nociceptive peripheral neuropathy following repeated cisplatin injections. Exp. Neurol. 182, 12-20. 
Brochet, D., Micó, J.-A., Martin, P., Simon, P., 1986. Antinociceptive activity of betaadrenoceptor agonists in the hot plate test in mice. Psychopharmacology 88 , 527-528.

Chen, K., Zhang, Z.-F., Liao, M.-F., Yao, W.-L., Wang, J., Wang, X.-R., 2015. Blocking PAR2 attenuates oxaliplatin-induced neuropathic pain via TRPV1 and releases of substance P and CGRP in superficial dorsal horn of spinal cord. J. Neurol. Sci. 352, $62-67$.

Cole, H.W., Brown, C.E., Magee, D.E., Magee, C., Roudebush, R.E., Bryant, H.U., 1995. Serotonin-induced paw edema in the rat: pharmacological profile. Gen. Pharmacol. $2,431-436$.

Colloca, L., Ludman, T., Bouhassira, D., Baron, R., Dickenson, A.H., Yarnitsky, D., Freeman, R., Truini, A., Attal, N., Finnerup, N.B., 2017. Neuropathic pain. Nature reviews Disease primers 3, 1-19.

Cuman, R., Bersani-Amado, C., Fortes, Z., 2001. Influence of type 2 diabetes on the inflammatory response in rats. Inflamm. Res. 50, 460-465.

Flatters, S.J., Bennett, G.J., 2004. Ethosuximide reverses paclitaxel-and vincristineinduced painful peripheral neuropathy. Pain 109, 150-161.

Fu, S.Y., Gordon, T., 1997. The cellular and molecular basis of peripheral nerve regeneration. Mol. Neurobiol. 14, 67-116.

Gawade, S.P., 2012. Acetic acid induced painful endogenous infliction in writhing test on mice. J. Pharmacol. Pharmacother. 3, 348-348.

Gilron, I., Baron, R., Jensen, T., 2015. Neuropathic pain: principles of diagnosis and treatment. In: Mayo Clinic Proceedings, vol. 90. Elsevier, pp. 532-545.

Gordon, T., Tyreman, N., Raji, M.A., 2011. The basis for diminished functional recovery after delayed peripheral nerve repair. J. Neurosci. 31, 5325-5334.

Halim, S.A., Khan, A., Csuk, R., Al-Rawahi, A., Al-Harrasi, A., 2020. Diterpenoids and triterpenoids from frankincense are excellent anti-psoriatic agents: an in silico approach. Frontiers in chemistry 8, 486.

Hughes, J.P., Chessell, I., Malamut, R., Perkins, M., Bačkonja, M., Baron, R., Farrar, J.T., Field, M.J., Gereau, R.W., Gilron, I., 2012. Understanding chronic inflammatory and neuropathic pain. Ann. N. Y. Acad. Sci. 1255, 30-44.

Hur, W., Chung, J.Y., Choi, P.K., Kang, H.G., 2019. Uremia presented as acute cranial neuropathy. Neurol. Sci. 40, 1487-1489.

Kaur, S., Muthuraman, A., 2020. Role of neuropeptides and ginsenoside Rg1 in peripheral nerve injury-induced neuropathic pain in mice. EC Pharmacology and Toxicology 8, 65-77.

Khan, S., Choi, R.J., Lee, J., Kim, Y.S., 2016. Attenuation of neuropathic pain and neuroinflammatory responses by a pyranocoumarin derivative, anomalin in anima and cellular models. Eur. J. Pharmacol. 774, 95-104.

Khan, S., Choi, R.J., Shehzad, O., Kim, H.P., Islam, M.N., Choi, J.S., Kim, Y.S., 2013. Molecular mechanism of capillarisin-mediated inhibition of MyD88/TIRAP inflammatory signaling in in vitro and in vivo experimental models. J. Ethnopharmacol. 145, 626-637.

Ledeboer, A., Jekich, B.M., Sloane, E.M., Mahoney, J.H., Langer, S.J., Milligan, E.D., Martin, D., Maier, S.F., Johnson, K.W., Leinwand, L.A., 2007. Intrathecal interleukin10 gene therapy attenuates paclitaxel-induced mechanical allodynia and proinflammatory cytokine expression in dorsal root ganglia in rats. Brain Behav. Immun. 21, 686-698.

Lee, S.E., Kim, J.-H., 2007. Involvement of substance P and calcitonin gene-related peptide in development and maintenance of neuropathic pain from spinal nerve injury model of rat. Neurosci. Res. 58, 245-249.

Lees, J.G., Duffy, S.S., Moalem-Taylor, G., 2013. Immunotherapy targeting cytokines in neuropathic pain. Front. Pharmacol. 4, 142.

Linardi, A., Costa, S.K., da Silva, G.R., Antunes, E., 2000. Involvement of kinins, mast cells and sensory neurons in the plasma exudation and paw oedema induced by staphylococcal enterotoxin B in the mouse. Eur. J. Pharmacol. 399, 235-242.

Liu, X.-J., Zhang, Y., Liu, T., Xu, Z.-Z., Park, C.-K., Berta, T., Jiang, D., Ji, R.-R., 2014. Nociceptive neurons regulate innate and adaptive immunity and neuropathic pain through MyD88 adapter. Cell Res. 24, 1374-1377.

Ma, W., Eisenach, J., 2003. Intraplantar injection of a cyclooxygenase inhibitor ketorolac reduces immunoreactivities of substance $\mathrm{P}$, calcitonin gene-related peptide, and dynorphin in the dorsal horn of rats with nerve injury or inflammation. Neuroscience 121, 681-690.

Manjavachi, M.N., Passos, G.F., Trevisan, G., Araújo, S.B., Pontes, J.P., Fernandes, E.S., Costa, R., Calixto, J.B., 2019. Spinal blockage of CXCL1 and its receptor CXCR2 inhibits paclitaxel-induced peripheral neuropathy in mice. Neuropharmacology 151, 136-143.

Munir, A., Khushal, A., Saeed, K., Sadiq, A., Ullah, R., Ali, G., Ashraf, Z., Mughal, E.U., Jan, M.S., Rashid, U., 2020. Synthesis, in-vitro, in-vivo anti-inflammatory activities and molecular docking studies of acyl and salicylic acid hydrazide derivatives. Bioorg. Chem. 104168.

Naveed, M., Khan, S.Z., Zeeshan, S., Khan, A., Shal, B., Atiq, A., Ali, H., Ullah, R., Khan, S., 2019. A new cationic palladium (II) dithiocarbamate exhibits antiinflammatory, analgesic, and antipyretic activities through inhibition of inflammatory mediators in in vivo models. N. Schmied. Arch. Pharmacol. 392, 961-977.

Onodera, N., Kakehata, A., Araki, I., 2013. Differential expression of GAP-43 protein in the rostral brain neurons of early chick embryos. Tohoku J. Exp. Med. 231, 293-298.

Pavao-de-Souza, G.F., Zarpelon, A.C., Tedeschi, G.C., Mizokami, S.S., Sanson, J.S., Cunha, T.M., Ferreira, S.H., Cunha, F.Q., Casagrande, R., Verri Jr., W.A., 2012. Acetic acid-and phenyl-p-benzoquinone-induced overt pain-like behavior depends on spinal activation of MAP kinases, PI3K and microglia in mice. Pharmacol. Biochem. Behav. 101, 320-328.

Polomano, R.C., Mannes, A.J., Clark, U.S., Bennett, G.J., 2001. A painful peripheral neuropathy in the rat produced by the chemotherapeutic drug, paclitaxel. Pain 94, 293-304.

Quasthoff, S., Hartung, H.P., 2002. Chemotherapy-induced peripheral neuropathy. J. Neurol. 249, 9-17.

Rodrigues, L.B., Oliveira Brito Pereira Bezerra Martins, A., Cesário, F.R.A.S., Ferreira e Castro, F., de Albuquerque, T.R., Martins Fernandes, M.N., Fernandes da Silva, B.A., Quintans Júnior, L.J., da Costa, J.G.M., Melo Coutinho, H.D., Barbosa, R., Alencar de Menezes, I.R., 2016. Anti-inflammatory and antiedematogenic activity of the Ocimum basilicum essential oil and its main compound estragole: in vivo mouse models. Chem. Biol. Interact. 257, 14-25.

Rukh, L., Ali, G., Ullah, R., Islam, N.U., Shahid, M., 2020. Efficacy assessment of salicylidene salicylhydrazide in chemotherapy associated peripheral neuropathy. Eur. J. Pharmacol. 173481.

Sałat, K., 2020. Chemotherapy-induced Peripheral Neuropathy: Part 1 -current State of Knowledge and Perspectives for Pharmacotherapy. Pharmacological Reports: PR.

Sandkuhler, J., 2009. Models and mechanisms of hyperalgesia and allodynia. Physiol. Rev. 89, 707-758.

Scripture, C.D., Figg, W.D., Sparreboom, A., 2006. Peripheral neuropathy induced by paclitaxel: recent insights and future perspectives. Curr. Neuropharmacol. 4, $165-172$.

Shahid, M., Subhan, F., Ahmad, N., Ali, G., Akbar, S., Fawad, K., Sewell, R.D.E., 2017a. Topical gabapentin gel alleviates allodynia and hyperalgesia in the chronic sciatic nerve constriction injury neuropathic pain model. Eur. J. Pain 21, 668-680.

Shahid, M., Subhan, F., Ahmad, N., Sewell, R.D., 2017b. The flavonoid 6-methoxyflavone allays cisplatin-induced neuropathic allodynia and hypoalgesia. Biomed. Pharmacother. 95, 1725-1733.

Singh, S., Majumdar, D., Rehan, H., 1996. Evaluation of anti-inflammatory potential of fixed oil of Ocimum sanctum (Holybasil) and its possible mechanism of action. J. Ethnopharmacol. 54, 19-26.

Sisignano, M., Baron, R., Scholich, K., Geisslinger, G., 2014. Mechanism-based treatment for chemotherapy-induced peripheral neuropathic pain. Nat. Rev. Neurol. 10, 694.

Subhan, F., Abbas, M., Rauf, K., Arfan, M., Sewell, R., Ali, G., 2010. The role of opioidergic mechanism in the activity of Bacopa monnieri extract against tonic and acute phasic pain modalities. Pharmacologyonline 3, 903-914.

Tapas, A.R., Sakarkar, D., Kakde, R., 2008. Flavonoids as nutraceuticals: a review. Trop. J. Pharmaceut. Res. 7, 1089-1099.

Tsutsumi, K., Kaname, T., Shiraishi, H., Kawashiri, T., Egashira, N., 2016. Polaprezinc reduces paclitaxel-induced peripheral neuropathy in rats without affecting antitumor activity. J. Pharmacol. Sci. 131, 146-149.

Ullah, R., Ali, G., Ahmad, N., Akram, M., Kumari, G., Amin, M.U., Umar, M.N., 2020. Attenuation of spatial memory in 5xFAD mice by halting cholinesterases, oxidative stress and neuroinflammation using a cyclopentanone derivative. Pharmaceuticals 13,318 .

Ur Rehman, N., Halim, S.A., Khan, M., Hussain, H., Yar Khan, H., Khan, A., Abbas, G., Rafiq, K., Al-Harrasi, A., 2020. Antiproliferative and carbonic anhydrase II inhibitory potential of chemical constituents from lycium shawii and aloe vera: evidence from in silico target fishing and in vitro testing. Pharmaceuticals 13, 94.

Vasudevan, M., Gunnam, K.K., Parle, M., 2007. Antinociceptive and anti-inflammatory effects of Thespesia populnea bark extract. J. Ethnopharmacol. 109, 264-270.

Vickers, N.J., 2017. Animal communication: when i'm calling you, will you answer too? Curr. Biol. 27, R713-R715.

Vitet, L., Patte-Mensah, C., Boujedaini, N., Mensah-Nyagan, A.-G., Meyer, L., 2018. Beneficial effects of Gelsemium-based treatment against paclitaxel-induced painful symptoms. Neurol. Sci. 39, 2183-2196.

Warwick, R., Hanani, M., 2013. The contribution of satellite glial cells to chemotherapyinduced neuropathic pain. Eur. J. Pain 17, 571-580.

Winter, C.A., Risley, E.A., Nuss, G.W., 1962. Carrageenin-induced edema in hind paw of the rat as an assay for antiinflammatory drugs. Exp. Biol. Med. 111, 544-547.

Yasar, H., Ersoy, A., Yazici, G., Suleyman, H., Ozgeris, F., Arslan, Y., Sunar, M., 2020. The Effect of Lutein on Paclitaxel-Induced Neuropathy and Neuropathic Pain in Rats.

Zhang, Y., Brewer, A.L., Nelson, J.T., Smith, P.T., Shirachi, D.Y., Quock, R.M., 2019. Hyperbaric oxygen produces a nitric oxide synthase-regulated anti-allodynic effect in rats with paclitaxel-induced neuropathic pain. Brain Res. 1711, 41-47. 